ADRIANA RODRIGUES RIBEIRO

\title{
Aspectos morfológicos da hipófise do macaco Cebus apella
}




\section{ADRIANA RODRIGUES RIBEIRO}

\section{Aspectos morfológicos da hipófise do macaco Cebus apella}

Tese apresentada ao programa de Pós-graduação em Anatomia dos Animais Domésticos e Silvestres da Faculdade de Medicina Veterinária e Zootecnia da Universidade de São Paulo, para obtenção do título de doutor em Ciências

\section{Departamento:}

Cirurgia

\section{Área de Concentração:}

Anatomia dos Animais Domésticos e Silvestres

\section{Orientadora:}

Prof $^{a}$. Dra. Irvênia Luiza de Santis Prada

São Paulo 
Autorizo a reprodução parcial ou total desta obra, para fins acadêmicos, desde que citada a fonte.

\section{DADOS INTERNACIONAIS DE CATALOGAÇÃO-NA-PUBLICAÇÃO}

(Biblioteca Virginie Buff D’Ápice da Faculdade de Medicina Veterinária e Zootecnia da Universidade de São Paulo)

T.1719

FMVZ

Ribeiro, Adriana Rodrigues

Aspectos morfológicos da hipófise do macaco Cebus apella / Adriana

Rodrigues Ribeiro . - São Paulo: Adriana Rodrigues Ribeiro , 2006.

89 f. : il.

Tese (doutorado) - Universidade de São Paulo. Faculdade de Medicina Veterinária e Zootecnia. Departamento de Cirurgia, 2006.

Programa de Pós-graduação: Anatomia dos Animais Domésticos e Silvestres.

Área de concentração: Anatomia dos Animais Domésticos e Silvestres.

Orientador: Profa. Dra. Irvênia Luiza de Santis Prada.

1. Neuroanatomia. 2. Cebus apella. 3. Glândula pituitária. I. Título. 


\title{
UNIVERSIDADE DE SÃO PAULO \\ Faculdade de Medicina Veterinaria e Zootecnia \\ Assistência Acadêmica
}

\author{
Comissão Bioética
}

\section{CERTIFICADO}

Certificamos que o Projeto intitulado "Morfologia da hipófise do macaco

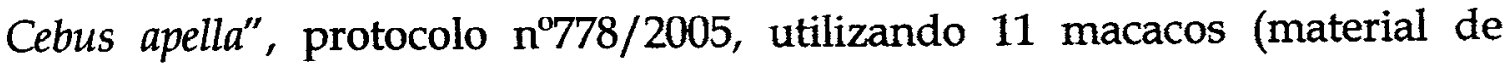
acervo do Laboratório de Anatomia), sob a responsabilidade da Profa. Dra. Irvênia Luiza de Santis Prada, está de acordo com os princípios éticos de experimentação animal da Comissão de Bioética da Faculdade de Medicina Veterinária e Zootecnia da Universidade de São Paulo e foi aprovado "ad referendun".

(We certify that the Research "Hypophisis morphology of Cebus apella monkey", protocol number 778/2005, under the responsibility of Profa. Dra. Irvênia Luiza de Santis Prada, utilizing 11 monkeys, agree with Ethical Principles in Animal Research adopted by Bioethic Commission of the Faculty of Veterinary Medicine and Zootechny of University of São Paulo and was approved "ad referendun", meeting).

São Paulo, 19 de outubro de 2005

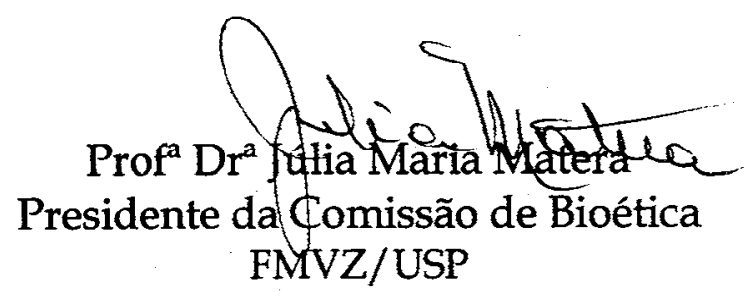




\section{FOLHA DE AVALIAÇÃO}

Nome: Ribeiro, Adriana Rodrigues

Título: Aspectos morfológicos da hipófise do macaco Cebus apella

Tese apresentada ao Programa de Pós-graduação em Anatomia dos Animais Domésticos e Silvestres da Faculdade de Medicina Veterinária e Zootecnia da Universidade de São Paulo para obtenção do título de Doutor em Ciências

Data:

1

\section{Banca Examinadora}

Prof. Dr. Instituição:

Assinatura: Julgamento:

Prof. Dr. Instituição:

Assinatura: Julgamento:

Prof. Dr. Instituição:

Assinatura: Julgamento:

Prof. Dr. Instituição:

Assinatura: Julgamento:

Prof. Dr. Instituição:

Assinatura: Julgamento: 
"Nõa é o desafio com que nos deparamos que determina quem somos e o que estamos nos tornando, mas a maneira com que respondemos aos desafios. Somos combatentes, idealistas, mas plenamente conscientes, porque ter consciência não nos obriga a ter teoria sobre as coisas, só nos obriga a ser conscientes. $\mathcal{E}$ enquanto acreditarmos no nosso sonho, nada é por acaso". 


\title{
Dedico
}

\author{
Aos meus pais Maria de Lourdes e Aguimar Antônio Ribeiro (in \\ memorian); \\ Às minhas irmãs Andréa e Amanda; \\ Aos meus avós Sebastiana Soares e Sebastião Rodrigues (in \\ memorian); \\ Aos meus primos Augusto César, Nelson e Sirlei; \\ Às minhas afilhadas Anna Laura e Larissa.
}

Amo Vocês!!!

Em paz com a vida e o que ela me traz, na fé que me faz otimista demais.

Se chorei ou se sorri o importante é que emoções eu vivi.

(Roberto Carlos e Erasmo Carlos) 


\section{Agradecimentos Especiais}

A Deus pela presença em todos os momentos e pela força na caminhada.

À Dra Irvênia Luiza de Santis Prada e ao Dr Zenon Silva

Pela amizade, conselhos, orientação, abraços $e$ risos. Vocês sempre estarão em meu coração como amigos queridos e eternos mestres. Obrigada por tudo!

"Aprender é a única coisa de que a mente nunca se cansa, nunca tem medo e nunca se arrepende".

(Leonardo da Vincci) 


\section{Agradecimentos}

Ao departamento de cirurgia da Faculdade de Medicina Veterinária e Zootecnia de São Paulo e ao corpo docente pelo curso ministrado.

À Dra Maria Angélica Miglino, coordenadora do curso de PósGraduação em Anatomia dos Animais Domésticos e Silvestres, pela oportunidade oferecida.

Ao Caboratório de Anatomia Humana da Universidade Federal de Uberlândia e ao IBAMA-MG, pela concessão do material de pesquisa e aos laboratórios de Histologia da UFU e da FMVZ-USP pela oportunidade de realização deste trabalho.

Ao Profo Doutor Marcos Silva pela orientação, disponibilidade e atenção dispensada a mim e a este trabalho.

À Profa Dra Gabriela Lícia Ferreira Santos pela disponibilidade em ajudar, pelos conhecimentos compartilhados, mas principalmente pela amizade, conversas e gargalhadas...

Aos funcionários e amigos, em Vberlândia: Anivanda, Hélgio, Lázaro, Jucélia, Thiago, Rui. Silvio e Vanderci, em São Paulo:

Claudia, Deise, Diogo, Edinaldo (Índio), Jaqueline, Maicon, Ronaldo e Sandra.

Aos professores de anatomia da Universidade Federal de Uberlândia pela amizade e exemplo profissional.

Aos amigos da Pós-Graduação por todos os momentos vividos nos laboratórios, dias de plantões, encontros e abraços.. Em especial Janaina, Karina Gagliardo, Lilian, Naianne, Rose Mary Viola.

Aos amigos do coração: Ádrya Soares, Almir e Maria Clara, Alex Lopes e Priscila, Alexandre Ribeiro, Daniela Cristina e Fábio Mitri, Flávio e Adriana, Fernanda Maria, Francielle e Adalto Jr., Jordana e Diogo, Joseni, Jupyracyara (Jupy's), Léa Cristina, Leandro e Luis Gustavo, Luciana Izquierdo (Bylfu), Magali, Márcio Buiatti e 
Danielle, Neydson, Noalle, Raquel Bernardes e Denise, Raquel Oliveira e Andryel, Regina Giaretta, Nielsen e Gabriela, Rodrigo Custódio, Rodrigo Lemes, Rogério Leles.

"Não sabemos dizer o momento preciso em que se forma a amizade. Ao enchermos um jarro gota a gota, a última faz o jarro transbordar, assim, numa série de gentilezas, há uma última que faz transbordar o coração. Muitas vezes, como a longevidade é geralmente desejada e, creio, geralmente esperada, seria aconselhável adicionar continuamente novos amigos de modo que a falta de uns possa ser suprida por outros. Assim a amizade, "o vinho da vida", tal como adega bem provida, deveria ser constantemente renovada; é consolador pensar que, embora raramente seja possivel a reposição no mesmo nível das generosas primeiras-safras da juventude, a amizade torna-se imperceptivelmente antiga em tempo, bem menor do que se imagina, e não são necessários muitos anos para se tornar madura e agradável. O calor faz, sem dúvida, considerável diferença.

Se um homem não trava novos conhecimentos à medida que avança pela vida, em breve se encontrará sozinho. Um homem deve manter a amizade em constante manutenção".

(James Boswell)

Em especial aos amigos-irmãos Herbert Levy e Roseâmely Angélica (Nega) por serem assim, sempre presentes.

"A gloria da amizade não é a mão estendida, nem o sorriso carinhoso, nem mesmo a delicia da companfia. É a inspiração espiritual que vem quando você descobre que alguém acredita e confia em você".

(Ralph Waldo Emerson)

$\mathcal{A}$ todas as pessoas que direta ou indiretamente contribuíram para a realização deste trabalho. 


\section{Resumo}

RIBEIRO, A. R. Aspectos morfológicos da hipófise do macaco Cebus apella. [Morphology Aspects of the Hipophisis of the monkey (Cebus apella)]. 2006. 89 f. Tese (Doutorado em Ciências) - Faculdade de Medicina Veterinária e Zootecnia, Universidade de São Paulo, São Paulo, 2006.

O conhecimento de diversos aspectos da Neuroanatomia de primatas não humanos - que atualmente é falho, pela falta de trabalhos a respeito - é importante não apenas pela importância intrínseca desse conhecimento como até pelo fato de contribuir para um melhor entendimento da própria evolução do grupo, o que representa um fator relevante para a sua preservação e proteção. O objetivo deste trabalho é efetuar estudos morfológicos da hipófise do macaco Cebus apella a fim de conhecer melhor esta estrutura, e oferecer subsídios para análises comparativas mais amplas. Utilizamos 11 animais sendo 7 deles constantes do acervo de pesquisa da Universidade Federal de Uberlândia e, os outros 4 exemplares, doados pelo IBAMA-MG. A preparação das peças anatômicas foi levada a efeito mediante cuidadosa dissecção dos espécimes, cujos encéfalos foram retirados das caixas cranianas, preservando-se ao máximo todas as suas estruturas. As hipófises, depois de registrada sua macroscopia, foram submetidas aos métodos histológicos de rotina para observações em microscopia de luz e eletrônica de transmissão. Dos resultados obtidos podemos citar que a hipófise, neste animal, é uma glândula intracraniana alojada na sela turcica, fixada à base do cérebro pelo infundíbulo, sendo este muito curto. Ela exibe forma odontóide, exibindo-se aparentemente, como uma massa única, pois macroscopicamente apenas é possível, a identificação de uma divisão discreta em um lobo anterior e outro posterior, além do infundíbulo. As análises histológicas mostram esta glândula dividida em três lobos: anterior (adenohipófise), intermédio e posterior (neurohipófise). À microscopia eletrônica de transmissão foi possível identificar e classificar 4 tipos celulares em relação á adenohipófise: células do tipo I, II, III e 
IV. O aspecto do núcleo dessas células, exibindo freqüentemente, invaginações profundas de sua membrana, confere à hipófise do macaco Cebus apella, características peculiares, o que nos instiga a realizar novas pesquisas sobre o assunto.

Palavras-chave: Neuroanatomia. Cebus apella. Glândula Pituitária. 


\section{Summary}

RIBEIRO, A. R. Morphology Aspects of the Hipophisis of the monkey Cebus apella [Aspectos morfológicos da hipófise do macaco Cebus apella]. 2006. 89 f. Tese (Doutorado em Ciências) - Faculdade de Medicina Veterinária e Zootecnia, Universidade de São Paulo, São Paulo, 2006.

The knowledge of many aspects of Neuroanatomy of non-human primates - which is currently poor due to the lack of studies on the subject - is very important not only for the intrinsic significance of the knowledge itself but also because it contributes for a better understanding of the evolution of the group, which represents a relevant factor for its preservation and protection. The objective of this study is to perform morphological researches on the hypophysis of the Cebus apella monkey in order to understand this structure better and to provide basis for wider comparative analyses. Eleven animals were used on this study. Seven of them were properties of the research collection of the Federal University of Uberlândia and the other four were donated by the IBAMA-MG. The preparation of the anatomical parts was carefully done through dissection of the specimens, whose encephalus were removed from their skulls preserving all their structures. The hypophysis, after having their macroscopy registered, were submitted to histological methods of routine for observation in light microscopy and electronic microscopy of transmission. We could conclude from the obtained results that the hypophysis, on this particular animal, is a intracranial gland lodged in the sela turcica fixed to the base of the brain by the infundibulum which is very short. It has in dens shape and it presents itself as a single mass, because, macroscopically, it is only possible the identification of a discrete division in an anterior lobe and another posterior one besides the infundibulum. The histological analyses show this gland divided in three lobes: anterior (adenohypophysis), intermediary and posterior (neurohypophysis). Through the electronic microscopy of transmission it was possible to identify and classify four cellular types related to the adenohypophysis: types I, II, III and IV. The aspect of the cores of these cells, frequently showing deep invaginations of their membranes, confers to hypophysis of the Cebus apella monkey, peculiar characteristics, which instigates us to carry on performing new studies on the subject

Key words: Neuroanatomy. Cebus apella. Pituitary gland. 


\section{Sumário}

1 INTRODUÇÃO

2 REVISÃO DA LITERATURA

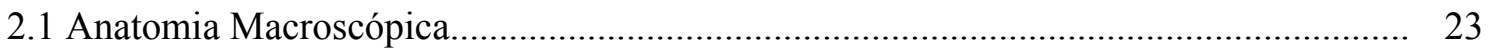

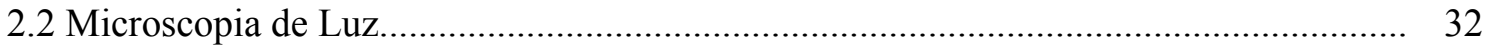

2.3 Microscopia Eletrônica de Transmissão.................................................................. 39

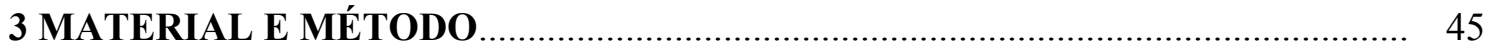

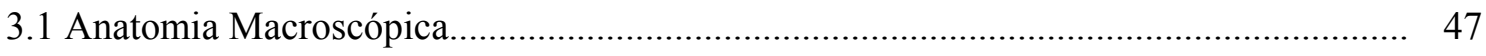

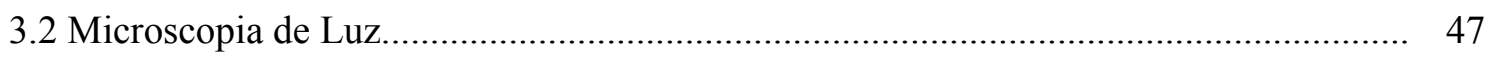

3.3 Microscopia Eletrônica de Transmissão............................................................... 50

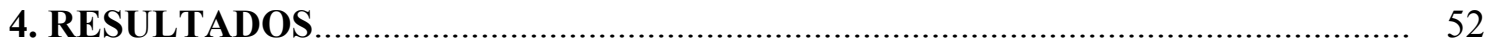

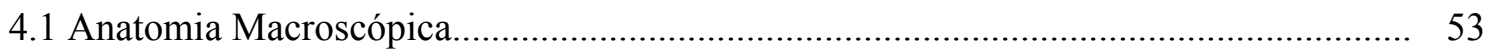

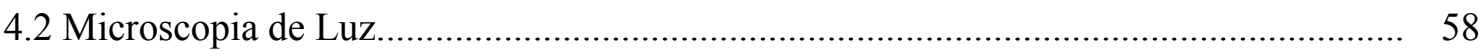

4.3 Microscopia Eletrônica de Transmissão............................................................... 64

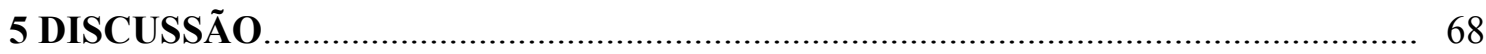

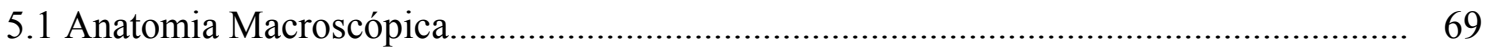

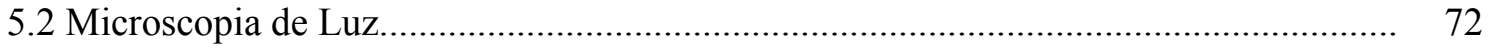

5.3 Microscopia Eletrônica de Transmissão.................................................................... 79

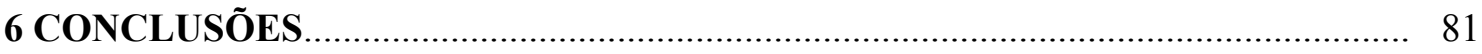

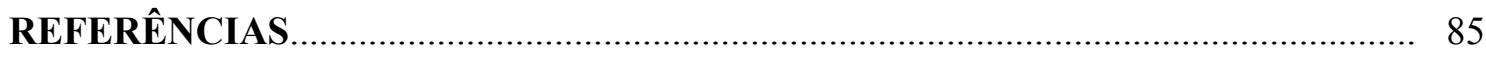


sis.

1 Introdução 
A Anatomia comparativa de mamíferos vem sendo tema de pesquisas, nas áreas biomédica e biológica, com o objetivo de se buscar conhecimentos que possam auxiliar na busca do entendimento do binômio unidade-variedade. Dentre os símios, tem sido enfocados particularmente o Babuíno e o Rhesus que, entretanto, não são próprios do Novo Mundo (RIBEIRO, 2002).

Refletem uma tendência das pesquisas em primatologia, no Brasil, as prioridades observadas na seguinte ordem de interesse e quantidade: ecologia e comportamento, reprodução e criação em cativeiro, sistemática, genética, fisio-patologia e citogenética. Nestes estudos destacou-se interesse pelos Callitriquídeos, Cebus e Alouatta (MELLO; FARIA, 1983).

Nas ultimas duas décadas houve um crescente interesse na utilização de primatas não humanos para estudos aplicáveis principalmente em reprodução humana, processos infecciosos, virologia humana e oncologia. Experimentos em símios refletem maior regularidade em processos fisiológicos e patológicos mais conclusivos para o homem do que outros resultados obtidos em experimentos com ratos, cobaias e outros animais de laboratórios (LAPIN, 1972).

O aumento descontrolado das grandes devastações e queimadas das matas brasileiras vêm ameaçando dia a dia a sobrevivência de muitas espécies nativas da nossa fauna. Entre elas destacamos o macaco-prego (Cebus apella), do gênero Cebus, que é um dos primatas mais importantes e estudados em nosso meio, além de outras espécies como micos, sagüis e bugios que também são motivos de nossa preocupação (PIZZUTTO, 2002).

O Cebus apella é um primata que se caracteriza por apresentar tamanho médio, em relação a outros primatas, podendo chegar a 5 ou $6 \mathrm{~kg}$, com pêlos pretos ou de vários matizes de cor castanho, mais comumente, castanho escuro. Os membros pélvicos são pouco mais 
longos do que os torácicos, os dedos possuem tamanho médio e são moderadamente diferenciados entre si. O terço distal da cauda é mais enrolado do que o restante, denotando razoável preensibilidade. A aparência da genitália externa pode gerar confusão, porque o clitóris é desenvolvido, à semelhança do pênis, e o escroto é séssil (NAPIER; NAPIER, 1967).

Esta espécie vive em grupos de 30 indivíduos em média. São onívoros, sendo a maior parte de sua dieta constituída de frutos e uma pequena quantidade de insetos. Outras partes das plantas, particularmente galhos novos e flores, bem como pequenos vertebrados são ingeridos menos freqüentemente. A destruição do habitat tem ameaçado progressivamente a sobrevivência de espécies do gênero Cebus, motivo pelo qual o estudo da vida desses primatas em cativeiro tem sua importância ressaltada (SANTINI, 1983).

A taxonomia é um meio de ordenar nossos conhecimentos sobre a biodiversidade através de uma série de estratégias convencionais. Para analisar a natureza, o homem adaptou sua intrínseca habilidade de classificar e elaborou formas mais adequadas para ordenar os seres vivos em grupos diferenciados de acordo com suas semelhanças. A divulgação destes dados requer uma uniformidade e se enquadra em uma nomenclatura taxonômica (AURICCHIO, 1995).

A classificação taxonômica da espécie estudada seguiu critérios de Wilson e Reeder (1992), conforme segue:

Reino: Animalia

Filo: Chordata

Classe: Mammalia

Ordem: Primates

Família: Cebidae

Gênero: Cebus

Espécie: Cebus apella (Linnaeus, 1758)

Nome popular: Macaco Prego 
São muito curiosos, removendo e quebrando coisas, sendo talvez o primata mais inteligente das Américas. Possui um cérebro muito circunvolucionado e pesado sendo, por esta razão e pela resistência às mudanças ambientais, utilizados em pesquisas biomédicas (AURICCHIO, 1995).

Dada a crescente discussão ética sobre a utilização de animais em pesquisas, a importância do conhecimento mais profundo de um território anatômico ou do corpo como um todo, de macacos, encontra-se cada vez mais alicerçada no interesse em se promover o bem-estar e a sobrevivência das diferentes espécies, do que em conservá-los como atividade meio aos fins humanos (PRADA, 2004) .

Quando trabalhamos com animais silvestres, ainda deparamos com uma grande escassez de dados na literatura, principalmente para assuntos específicos. Espécies de primatas como Rhesus, Babuíno, Cinomolgo, Chimpanzé, macaco de Formosa e outros têm, hoje, sua Anatomia consideravelmente bem conhecida e descrita. Contudo, o Cebus apella, em que pese sua importância como integrante de ecossistemas brasileiros, permanece sem um padrão anatômico conhecido e descrito, o que por si só justifica nosso interesse no desenvolvimento da pesquisa ora apresentada.

Seguem-se breves descrições dos grupos de primatas.

Os primatas superiores são divididos em dois grandes grupos: Primatas do Velho Mundo (Hominóides - Humanos, Chimpanzés, Bonobos, Gorilas, Orangotango, Babuínos e Macaco Rhesus) e Primatas do Novo Mundo (Bugios, Macaco-prego e Macaco-aranha) (VERAS, 2004). Também são distribuídos conforme a chave taxonômica a seguir:

SUBORDEM Prosimii: os prosímios são os primatas mais primitivos. O grupo mais importante é o dos lêmures. 
Ex: Eulemur coronatus e Lemur catta

SUBORDEM Anthropoidea: A divisão taxonômica e geográfica mais importante entre os primatas antropóides ocorre entre os Platirrhini (primatas neotropicais) e os Catarrhini (primatas do velho mundo, grandes primatas e humanos).

INFRAORDEM Catarrhini:

SUPERFAMÍLIA Cercopithecoidea: É composta por uma única família dividida em duas subfamílias (Colobinae e Cercopithecinae). Que podem ser encontrados na África, Ásia e Japão vivendo em uma grande variedade habitats. Primatas da subfamília Cercopithecinae (babuínos) são muito utilizados em pesquisas biomédicas.

Ex: Macaca fascicularis, Macaca mulatta, Macaca radiata, Papio papio, Presbytis obscura e Colobus grereza

SUPERFAMÍLIA Hominoidea: É composta pelos primatas que não possuem cauda e possuem postura semi-ereta. Está dividida em três famílias: Hylobatidae, Pongidae e Hominidae.

FAMÍLIA Hyalobatidae: São primatas hominóides encontrados no sudeste asiático, são exclusivamente arbóreos e especializados para braquiação.

Ex: Hyalobates lar e Hyalobates agilis

FAMÍLIA Pongidae: Esta família é composta pelos grandes primatas que estão divididos em três gêneros: Pongo (orangotangos), Gorilla (gorilas) e Pan (chimpanzés e bonobos).

Ex: Pongo pygmaeus, Gorilla gorilla e Pan tryglotides

INFRAORDEM Platirrhini: São primatas que vivem quase que exclusivamente nas matas tropicais da América do Sul e Central. Estão divididos em cinco famílias: Callithrchidae, Cebidae, Aotidae, Pitheciidae e Atelidae. 
FAMÍLIA Callithrichidae: são primatas pequenos e monogâmicos, os representantes mais conhecidos desta família são os sagüis e os micos.

Ex: Callithrix jacchus e Leontopithecus chrysomelas

FAMÍLIA Cebidae; Dividida em três gêneros de primatas de médio porte, cujos representantes podem ser encontrados nas regiões tropicais e subtropicais.

Ex: Saimiri sciureus e Cebus apella

FAMÍLIA Aotidae: Esta família possui apenas um gênero Aotus, são primatas pequenos de hábitos noturnos, encontrados nas regiões tropicais da América do Sul.

Ex: Aotus azarae e Aotus trivirgatus

FAMÍLIA Pitheciidae: Composta por quatro gêneros: Callicebus, Pithecia, Chiropotes e Cacajao antes incluídos na família Atelidae. São primatas que habitam a bacia Amazônica e as Guianas.

Ex: Cacajao calvus, Pithecia pithecia, Callicebus personatus e Chiropotes monachus.

FAMÍLIA Atelidae: Abrange os gêneros dos maiores Platyrrhini (Ateles, Alouatta, Brachyteles, Lagothrix e Oreonax), sua característica principal é a cauda preênsil com palma e de grande habilidade.

Ex: Ateles geoffryei, Brachyteles arachnoides, Lagothrix lagotricha, Alouatta guariba, Alouatta caraya, Alouatta seniculus, Alouatta belzebul e Alouatta palliata

A abordagem de diversos aspectos da Neuroanatomia de primatas não humanos - que atualmente é falho, pela falta de trabalhos a respeito - é importante não apenas pela importância intrínseca desse conhecimento como até pelo fato de contribuir para um melhor entendimento da própria evolução do grupo, o que representa fator relevante para a sua preservação e proteção. 
Por outro lado, recentemente tem-se enfocado com bastante interesse, em nosso meio de trabalho, o estudo de aspectos neuroanatômicos do Cebus apella, visando seu conhecimento. Neste trabalho analisaremos aspectos macroscópicos e microscópicos da Hipófise desta espécie.

Segundo Reis (1988), em seu relato sobre a hipófise do gambá, cita que a hipófise de um modo geral é uma glândula de secreção interna que produz importantes hormônios. Formada a partir de dois divertículos ectodérmicos, um do teto da cavidade bucal (bolsa de Rathke) e outro do assoalho do terceiro ventrículo (infundíbulo), guarda na maioria das espécies uma separação morfofuncional relacionada com a duplicidade da origem. A bolsa de Rathke irá constituir o lobo anterior (pars distalis e pars tuberalis) e a pars intermédia, cujas células de natureza epitelial produzem a maioria dos hormônios da glândula. O divertículo diencefálico irá constituir o lobo posterior e o infundíbulo.

Embora conhecida pelos anatomistas desde Galeno (130 - 210 d.C.), foi considerada durante muito tempo um órgão rudimentar. Sua importância passou a ser reconhecida desde os fins do século XIX e começo do século XX, quando se iniciou um prodigioso ciclo de experimentos envolvendo a extirpação da glândula e a observação dos efeitos que isto resultava nas demais glândulas e mesmo no organismo como um todo.

Pode-se dizer que os primeiros estudos citológicos da hipófise surgiram com o advento da microscopia em meados do séc. XIX, pois em sua revisão, Romeis ${ }^{1}$ (1940 apud REIS, 1988, p. 02) faz referência a publicações que datavam a partir de 1844; porém as primeiras referências alusivas à identificação de tipos celulares na hipófise só vieram no final do séc.

\footnotetext{
${ }^{1}$ ROMEIS, B. Hipophyse. In Handbuch der mikroskopischen anatomie des menschen, W. Von Mollendorff, Berlim. Springer, 1940, Teil 6, Band 3.
} 
XIX, cabendo a Schonemann² (1892 apud REIS, 1988, p. 02) fazer as primeiras referências à presença de células cianófilas e eosinófilas na hipófise.

A despeito de seu tamanho, segundo BLOOM; FAWCETT (1977), a hipófise é um dos órgãos mais importantes do corpo. Produz pelo menos nove hormônios e apresenta várias inter-relações com outras glândulas endócrinas. Também mostra conexões neurais e vasculares com o encéfalo, ao qual está ligada por um curto pedúnculo. Devido a essas conexões, a hipófise ocupa uma posição de destaque na interação do sistema nervoso com o endócrino - os dois grandes sistemas de integração do corpo.

Diante do exposto e dando seqüência ao estudo de aspectos anatômicos do macaco Cebus apella (BARROS, 2003; RIBEIRO, 2005), propomo-nos a investigar a organização morfológica da hipófise, com o objetivo de melhor conhecê-la e oferecer subsídios para análises comparativas mais amplas.

O objetivo a médio e longo prazos é o estabelecimento do padrão anatômico deste animal, culminando com a elaboração de um Atlas- texto sobre a Anatomia do macaco Cebus apella.

\footnotetext{
${ }^{2}$ SCHÖNEMANN, A. Hypophysis und Thyreoidea. Virchows Arch. 129: 310 - 336, 1892.
} 


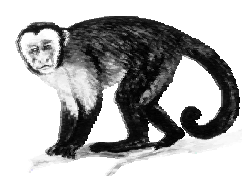

2 Revisão da Literatura 


\subsection{Anatomia Macroscópica}

Miller e Leonard (1932, p. 266) descrevem para o macaco Rhesus que a hipófise é, em geral, notavelmente semelhante à do homem. Ela consiste de três lobos, o lobo anterior, lobo posterior, e lobo intermédio. Aloja-se profundamente em uma cavidade óssea, a sela turcica. Posteriormente, a hipófise limita-se pela parede dorsal da sela que se estende dorsoanteriomente recobrindo a maior parte do lobo posterior e parte do lobo anterior. $\mathrm{O}$ assoalho da sela não é tão plano como o do homem, apresenta forma triangular, com o ápice que se estende anteriormente a um nível mais alto que a base.

Lateralmente, dobras da dura-mater separam a hipófise da parede mediana dos seios cavernosos por onde passam as artérias carótida internas. As dobras laterais são contínuas na face anterior para formar parte da borda anterior da hipófise e são dorsalmente contínuas sobre a própria hipófise. Outra membrana dural é localizada dorsalmente à hipófise e se estende anteriormente aos processos clinóides posteriores. Isto se denomina diafragma da sela. Embora a borda dorsal anterior da hipófise pareça estar na sela turcica, existe um espaço entre o diafragma da sela e a membrana que cobre a base da sela turcica anteriormente, que é o seio intercavernoso. Assim, a hipófise é completamente inclusa em uma membrana dural com exceção da abertura feita pela haste por intermédio da qual une seu lobo posterior ao hipotálamo.

As duas artérias carótidas internas no macaco Rhesus, segundo Miller e Leonard (1932, p. 266), passam anterodorsalmente nos seios cavernosos, perfurando o diafragma da sela anterolateralmente ao infundíbulo. O quiasma ótico situa-se anterodorsalmente à hipófise. 
A hipófise tem forma ovóide e mede aproximadamente 3-4mm antero-posteriormente, $4 \mathrm{~mm}$ dorsoventralmente, e aproximadamente $6-7 \mathrm{~mm}$ em largura. (Estas medidas são das 2 fêmeas adultas que pesaram aproximadamente $3,5-4 \mathrm{Kg}$ cada). O lobo anterior pode ser distinguido por sua coloração avermelhada, uma indicação de sua função glandular, enquanto que o lobo posterior é de tecido cerebral. O lobo anterior tem relativamente a forma de feijão. O lobo posterior pode estender-se posteriormente ao ângulo formado pelo teto e assoalho da sela turcica. A forma da sela faz este lobo estar localizado bem no acidente ósseo, mais do que o lobo anterior.

O lobo posterior é fixado ao hipotálamo por uma haste de aproximadamente 2-4 $\mathrm{mm}$ de comprimento. Uma cavidade muito pequena pode ser vista estendendo-se da parte inferior do $3^{\circ}$ ventrículo na própria haste. Em um espécime injetado com tinta da Índia, pequenos vasos podem ser vistos sob o microscópio binocular em toda a extensão do infundíbulo até a abertura do diafragma da sela. O tamanho pequeno deles impediu qualquer tentativa para localizá-los na própria hipófise. Como a hipófise está rodeada com artérias grandes e amplos seios venosos, vasos de tamanho pequenos ou médios para a glândula não foram encontrados.

Hill (1955) descreve para o Tarsius que a hipófise é globular com 2,5 mm de diâmetro, ocupa a fossa hipofisária e é revestida pela dura-máter, formando o diafragma da sela com o quiasma óptico dorsal a este. Lateralmente, ela se relaciona com os seis cavernosos e os nervos cranianos próximos às suas paredes. A glândula apresenta um lobo distal amplo, uma pequena parte intermediária e uma parte nervosa.

O lobo distal dispõe-se de forma a abraçar a parte nervosa e uma fenda extensa entre ela e a parte intermédia foi identificada. 
A parte intermédia consiste de uma única lâmina de tecido epitelial aderida à parte nervosa, não apresentando material coloidal nas secções. A parte nervosa consiste somente de neuroglia; ela é sólida, assim como o infundíbulo que a conecta ao tuber cinério.

Hanström $^{1}$ (1948, 1952, 1953 apud Hill (1957, p.168) descreve a hipófise em duas espécies de Hapale (H. jacchus e H. penicillata) e em Tamarinus nigricollis. Em todas, o órgão é amplo e de forma circular provido de uma curta haste principal; o recesso infundibular é superficial e, a haste, sólida. A pars tuberalis forma um colar ao redor do infundíbulo e também liga o processo ventral de cada lado da pars distalis (pars teberalis interna).

Para os Cebídeos, Hill (1960) descreve que esta glândula tem forma ovóide e achatada medindo $5 \mathrm{~mm}$ de espessura, $4 \mathrm{~mm}$ de largura e 2, $6 \mathrm{~mm}$ de comprimento. Sua coloração em geral é de rosa a castanho, sendo que o lobo posterior é mais escuro que o anterior, e de consistência delicada. Especificamente para o Cebus apella o autor relata que esta glândula apresenta 2,8 $\mathrm{mm}$ de comprimento e 4,5 $\mathrm{mm}$ de largura, do qual o lobo anterior é estimado em 2,8 mm. A pars intermédia alcança no máximo $0,6 \mathrm{~mm}$, e é separada por uma fenda estreita do lobo anterior. No feto ela é mais desenvolvida. O infundíbulo tem 2,0 $\mathrm{mm}$ de comprimento. A pars tuberalis está presente sobre o lado ventral do infundíbulo e haste, entendendo acima em contato imediato com a parte distal.

Hill (1966) descreve para os Miopithecus que a hipófise é relativamente larga, medindo 4,5mm de diâmetro transversal, 3,5 $\mathrm{mm}$ anteroposteriormente e 2,8 $\mathrm{mm}$ de comprimento. O infundíbulo é rodeado por um colar de tecido tuberal. O lobo anterior abraça

\footnotetext{
${ }^{1}$ HANSTRÖM, B. 1948. K. Fysiogr.Sallsk.Handl., N.F. lix. No.10 HANSTRÖM, B. 1952. Lunds Univ. Ärsskr., N.F Avd. 2 x1viii. 3-12. HANSTRÖM, B. 1953. Ark. Zoll. Stockh. vi. 95-154.
} 
a pars nervosa, que tem um contorno triangular com base medindo 3,5 $\mathrm{mm}$ transversalmente.

Para os Cercopithecus, o mesmo autor relata que a hipófise tem formato de ervilha, está alojada na sela turcica e projeta-se posteriormente para o dorso da sela e posterior ao processo clinóide. O órgão é menos achatado que no Miopithecus. A parte anterior (pars bucalis) é de consistência firme exatamente diferenciada da textura mais esponjosa da pars nervosa. A pars tuberalis forma um colar ao redor do infundíbulo assim como em algumas espécies de Cercopithecus.

Para os Allenopithecus, Hill (1966) cita que a hipófise é semelhante ao mesmo órgão dos Cercopithecus e Miopithecus. Ela é formada por um tecido neural, sendo que a pars bucalis cobre, formando um círculo, à frente e os lados da pars nervosa e mostra, anteriormente, um sulco profundo formado pela pressão da artéria carótida interna.

Hanström² $^{2}$ 1958, apud Hill, 1966, p. 66), estudando a hipófise no Gorila, chimpanzé e Papio, relata que a pars tuberalis forma um colar ao redor do infundíbulo e uma extensão posterior da pars distalis cobre a pars nervosa próximo à junção com o infundíbulo.

Bloom e Fawcett (1977) citam para o homem que a hipófise apresenta duas grandes subdivisões: a neurohipófise, que se desenvolve como um prolongamento que cresce a partir do assoalho do diencéfalo, e a adenohipófise, que se origina como uma evaginação dorsal do teto da faringe embrionária. Há três subdivisões da adenohipófise: a parte distal ou lobo anterior, a parte tuberal ou infundibular, e a parte intermediária. A neurohipófise está dividida, geralmente, em 3 regiões: a eminência média, uma extensão afunilada do tuber cinéreo, a haste infundibular e o processo infundibular (parte nervosa).

\footnotetext{
${ }^{2}$ HANSTRÖM, B. 1958. Hypophysis. Primatologia iii (1), 705-751. Basel, Krager.
} 
Em muitas espécies, a parte intermediária adere intimamente ao processo infundibular para formar o lobo posterior, separado da parte distal ou lobo anterior, por uma fenda. No homem, a fenda está bastante obliterada no período fetal e na vida pós-natal, de tal forma que os lobos anterior e posterior apresentam-se contínuos.

Segundo os mesmos autores, a hipófise está situada numa depressão profunda do osso esfenóide, a sela túrcica; encontra-se coberta por um diafragma resistente, o diafragma da sela. Esta barreira entre a sela túrcica e a cavidade intracranial geralmente é incompleta, sendo penetrada por uma abertura de $5 \mathrm{~mm}$ ou mais de diâmetro em torno da haste hipofisária. Uma parte da pia-aracnóide tem possibilidade de se entender através dessa abertura e ocupar o estreito espaço entre o diafragma e a cápsula conjuntiva da glândula. Em outra parte da glândula, a cápsula colágena densa está separada do periósteo do osso esfenóide por uma camada de tecido conjuntivo frouxo com numerosas veias. Esta camada parece estar separada da pia-aracnóide. Nos mamíferos, como no homem, o diafragma da sela é geralmente incompleto.

Brodal (1979) descreve para o homem, que a hipófise ou glândula pituitária consiste de um lobo anterior, a adenohipófise, e um lobo posterior, ou neurohipófise. A primeira é embriológicamente desenvolvida a partir do epitélio da faringe primitiva como bolsa de Rathke; a última, a partir do tubo neural. Os dois lobos principais podem ser ainda subdivididos, sendo a subdivisão mais comumente usada, a seguinte: o corpo do lobo anterior é formado por sua pars distalis, pela pars tuberalis rostralmente e a pars intermedia inferiormente. A neurohipófise consiste de uma eminência mediana do tuber cinéreo, o pedúnculo infundibular sendo inferior a ele, e ao processo infundibular ou lobo neural.

Willians et al. (1995) descrevem para o homem que a hipófise (glândula pituitária) é um corpo ovóide, cinza-avermelhado, medindo cerca de $10 \mathrm{~mm}$ de diâmetro transverso e 8 
$\mathrm{mm}$ de diâmetro antero-posterior e pesando aproximadamente 500mg. É contínua com o infundíbulo, um processo inferior, cônico, côncavo, proveniente do túber cinéreo do hipotálamo. Ela situa-se dentro da fossa hipofisária do osso esfenóide, coberta superiormente por um diafragma da sela, circular, da dura-máter do encéfalo; este é perfurado centralmente por uma abertura para o infundíbulo e separa a face superior anterior da hipófise, do quiasma óptico. A hipófise é flanqueada pelos seios cavernosos e suas estruturas relacionadas. Inferiormente, é separada do assoalho de sua fossa por um seio venoso que se comunica com o seio circular. As meninges fundem-se com a cápsula hipofisária e não são lâminas separadas.

A designação das divisões e subdivisões da hipófise continuam os autores, é um tanto confusa. A divisão principal é em duas regiões, que diferem em origem, estrutura e função; a primeira é uma evaginação descendente do diencéfalo unida com o hipotálamo; a outra é um derivado ectodérmico do estomódio. Estas são, respectivamente, a neurohipófise e a adenohipófise. Ambas incluem parte do, que possui um pedúnculo infundibular central, contendo conexões hipofísárias neurais, sendo contínuo com a eminência mediana do túber cinéreo. Assim, o termo neurohipófise inclui a eminência mediana, o pedúnculo infundibular e o lobo neural ou parte posterior, e também uma extensão da adenohipófise, circundando principalmente o pedúnculo infundibular neural, a pars tuberalis ou infundibularis.

A massa principal da adenohipófise é dividida em pars distalis (pars anterior) e pars intermedia, separada, na vida fetal e no inicio da vida pós-natal, pela fenda hipofisária, um vestígio da bolsa de Rathke, da qual se desenvolve. Geralmente obliterada na infância, pode persistir em forma de cavidades císticas freqüentemente presentes próximo da fronteira adeno-neuro-hipofisária, e algumas vezes invadindo o lobo neural. A pars intermedia humana, assim como as partes anterior e posterior (pars nervosa) podem ser equiparadas com 
os lobos anterior e posterior. Quando as partes infundibulares associadas, contínuas com estes lobos estão incluídas, os nomes adenohipófise e neurohipófise se tornam apropriados. Os termos, por esta razão, serão usados como se segue: - Neurohipófise: inclui a pars nervosa (pars posterior, lobo neural ou posterior, que é uma evaginação descendente do assoalho do diencéfalo e, no início da vida fetal, contém uma cavidade contínua com o terceiro ventrículo, que persiste em alguns animais, como nos gatos), pedúnculo infundibular e eminência mediana. - Adenohipófise: inclui a pars distalis (pars anterior ou glandularis), pars intermedia e pars tuberalis.

Junqueira (2004) descreve para o homem que a hipófise é um pequeno órgão, pesando cerca de $0,5 \mathrm{~g}$ no adulto. Localiza-se na sela túrcica do osso esfenóide e liga-se, por um pedúnculo, ao hipotálamo na base do cérebro, com o qual guarda importantes relações anatômicas e funcionais.

Ela tem origem embriológica dupla: nervosa e ectodérmica; a porção de origem nervosa provém de um crescimento do assoalho do diencéfalo que se desenvolve em direção caudal, não perdendo o contato com o encéfalo, de modo a formar um pedúnculo. $O$ ectoderma do teto da cavidade oral primitiva cresce em direção cranial, formando a bolsa de Rathke; posteriormente, uma constrição na base desta bolsa separa-a da cavidade bucal. Ao mesmo tempo, a parede anterior se espessa, diminuindo o tamanho do lúmen da bolsa de Rathke, que fica reduzido a uma pequena fissura.

A porção de origem nervosa é denominada neurohipófise e consta de uma porção volumosa, a pars nervosa, e do seu pedúnculo, o infundíbulo. Este se continua com o hipotálamo, constituindo a ligação entre a hipófise e o sistema nervoso central, representado pelo hipotálamo, pois através do infundíbulo passam importantes tratos nervosos e substâncias que irão atuar sobre a adenohipófise. 
A porção originada do ectoderma é denominada adenohipófise e está subdividida em três porções. A primeira é a mais volumosa, a pars distalis ou lobo anterior, a segunda é a porção cranial que envolve o infundíbulo, denominada pars tuberalis e a terceira é uma região intermediária entre a neurohipófise e a pars distalis, separada desta última pela fissura restante da cavidade da bolsa de Rathke. Esta porção recebeu o nome de pars intermédia.

Ao conjunto de pars nervosa e pars intermédia dá-se o nome de lobo posterior da hipófise. A glândula é revestida por uma cápsula de tecido conjuntivo contínua com a rede de fibras reticulares que suporta as células do órgão.

A neurohipófise consta da pars nervosa e do infundíbulo que une a glândula ao hipotálamo. Ao contrário das outras partes da hipófise que possuem características epiteliais, a neurohipófise é formada por axônios amielínicos de células nervosas secretoras. Os corpos celulares desses neurônios não se localizam na própria hipófise, mas sim, nos núcleos supraópticos e paraventriculares e também, em menor número, em outros pontos do hipotálamo.

Didio (2002) descreve para o homem, que a hipófise é uma glândula intracranial, relativamente pequena (com o tamanho aproximado de uma ervilha grande), localizada na tela túrcica do osso esfenóide. Ela está ligada ao hipotálamo por meio de uma haste, o infundíbulo, que atravessa uma pequena abertura no diafragma da sela, uma lâmina da duramáter que forma o teto da tela túrcica. De acordo com Wislocki³ (1937apud DIDIO, 2002), a hipófise é revestida pela dura-máter, mas não pela aracnóide ou pia-máter. O infundíbulo acha-se no espaço subaracnóideo, mas este não chega à tela túrcica.

A hipófise está dividida em adenohipófise (lobo anterior), embriologicamente derivada da bolsa de Rathke, um divertículo da extremidade superior da faringe, e neurohipófise (lobo

\footnotetext{
${ }^{3}$ WISLOCKI, G. B. - 1937 - The meningeal relations of the hypophysis cerebri, part II, an embryological study of the meninges and blood
} 
posterior), embriologicamente derivada do cérebro.

A adenohipófise, que é achatada súpero-inferiormente e côncava posteriormente (a neurohipófise encaixa-se nessa concavidade), compreende uma parte distal, uma tuberal e uma intermédia. A parte distal, a maior delas, está localizada anteriormente ao lúmen residual; a parte intermédia está situada entre o lúmen residual e a neurohipófise, e a parte tuberal é uma extensão superior da parte intermédia ao longo do infundíbulo.

Certa confusão surgiu porque a presença da luz residual entre a parte intermédia e a parte distal tinha levado muitos autores a considerarem a parte intermédia como parte do lobo posterior ou como um lobo separado.

A neurohipófise (ou lobo posterior) está diretamente ligada ao hipotálamo por meio do infundíbulo.

A neurohipófise deve ser considerada constituída pelo lobo posterior, o infundíbulo (haste) e a eminência mediana do hipotálamo.

A glândula relaciona-se superiormente com o quiasma óptico e com os tractos ópticos, lateralmente com a artéria carótida interna e as outras estruturas do seio cavernoso. O seio esfenoidal situado inferior e anteriormente à hipófise e a camada óssea existente entre essas duas estruturas freqüentemente é fina. Não há nervos conhecidos no lobo anterior, com exceção dos que seguem os vasos sanguíneos. Entretanto, a neurohipófise tem conexão direta com o cérebro, sendo essa parte da glândula inervada por fibras de neurônios que se localizam no hipotálamo. Estes neurônios contêm, nos seus corpos celulares e axônios, grânulos de neurossecreção. Supõe-se que os hormônios produzidos pela neurohipófise sejam realmente secretados por esses neurônios e armazenados no lobo posterior. 


\subsection{Microscopia de Luz}

Hill (1953) descreve, para Strepsirhini, que a glândula pituitária é bem desenvolvida e seus lobos são definidos. Sua forma geral é a de uma esfera achatada. Blair Bell ${ }^{4}$ (1919, apud Hill (1953, p. 78), estudando a glândula pituitária de um único espécime de Lemur catta, observou que a pars intermedia estava presente recobrindo anteriormente a pars nervosa $\mathrm{e}$ anteroinferiormente o infundíbulo; foi observado também que este tecido formou ilhotas sólidas dentro da pars nervosa. Suas células foram coradas profundamente com corantes básicos. Nas pars anterior, eosinófilos foram muito evidentes, organizados em ramificações colunares; cromófobos ativos foram corados fracamente com corantes básicos.

Hill (1957) relata, para as espécies de Hapale e para Tamarinus nigricollis, que existe uma zona tuberalis exclusivamente composta de células basófilas e cromófobas ocupando uma extensa área da parte mediana anteroventral da pars distalis. A pars intermédia é composta de muitas células largas, com dimensões de células cromófilas de pars distalis.

O lobo neural contém numerosas massas coloidais coradas de vermelho com azan, e também numerosas dilatações nas terminações nervosas, especialmente na eminência mediana, a haste infundibular e o processo infundibular. Tamarinus e Hapale mostram diferenças na fenda intraglandular.

Em 1960 Hill descreve para o Cebus apella que as células da pars tuberalis são caracterizada pelos seus pequenos núcleos.

Bloom e Fawcett (1977) relatam, para o homem, que a maior parte da hipófise é a parte distal (ou lobo anterior) que apresenta células glandulares dispostas em cordões

\footnotetext{
${ }^{4}$ BELL, W. BLAIR. 1919. The Pituitary, London
} 
irregulares ou acúmulos, que estão intimamente relacionados com um vasto sistema de paredes delgadas - os sinusóides do sistema vascular sanguíneo. O lobo anterior encontra-se amplamente envolvido por uma cápsula colágena densa. O estroma da glândula não é abundante, mas algumas fibras colágenas, que acompanham as artérias hipofisárias superiores e as vênulas portais invadem o lobo anterior no pólo adjacente à parte tuberal e espandem-se bilateralmente. Tornam-se contínuas com as fibras reticulares que envolvem os cordões de células parenquimatosas e sustentam os pequenos ramos da artéria hipofisária e os sinusóides. Embora o revestimento endotelial dos sinusóides tenha sido tradicionalmente considerado como fagocítico, como o do fígado, isso não tem sido demonstrado pela microscopia eletrônica. Por essa razão, os sinusóides não são considerados integrantes do sistema reticuloendotelial. Os sinusóides na periferia da glândula continuam-se com as vênulas coletoras que ligam um extenso plexo venoso na cápsula.

As células glandulares, como citam Bloom e Fawcett (1977), são classificadas como cromófilas e cromófobas, baseando-se na sua avidez ou falta de afinidades por corantes usados nas colorações rotineiras de cortes histológicos. As células cromófilas foram, a princípio, subdivididas em células acidófilas e basófilas, de acordo com as reações tintoriais dos seus grânulos específicos nos cortes corados com hemalúmen e eosina ou com outras combinações de um corante básico e um ácido.

Para esses autores, é importante compreender que os termos acidófilos e basófilos, como usaram os citologistas da pituitária, não têm a mesma conotação com respeito à química do citoplasma, de outros campos da Citologia. A basofilia dos grânulos na célula basófila da pituitária não deve ser confundida com aquela que resulta da ribonucleoproteína nas outras células glandulares. Na denominação das células da pituitária, acidófilo e basófilo referem-se apenas às afinidades tintoriais dos grânulos específicos. A cor dos grânulos pode ser 
vermelha, laranja, púrpura ou azul, dependendo da combinação de corantes ácidos usada. Com os métodos tricrômicos de coloração, tem sido necessário estabelecer a relação dos tipos celulares com o tradicional acidófilo, basófilo e as categorias cromófobas, comparando-se as mesmas células em cortes seriados corados com misturas tricrômicas e com hematoxilinaeosina.

A parte tuberal (ou infundibular), segundo Bloom e Fawcett (1977) é uma pequena parte da hipófise, e assim como a parte intermediária é adjacente e contínua ao lobo anterior. Apresenta 25 a $60 \mu \mathrm{m}$ de espessura e envolve a haste, estando a porção mais espessa sobre a sua superfície anterior. Freqüentemente mostra-se incompleta na superfície posterior da haste. A característica morfológica diferencial da parte tuberal é a disposição longitudinal de seus cordões de células epiteliais, as quais ocupam os interstícios entre os vasos sanguíneos orientados longitudinalmente. Esta parte é a mais vascularizada da hipófise, por ser atravessada pelo principal suprimento arterial do lobo anterior e pelo sistema venoso portal hipotalâmico-hipofisário. A parte tuberal está separada da haste infundibular por uma delgada camada de tecido conjuntivo contínuo com a pia-mater. Na parte voltada para fora, o tecido conjuntivo é uma típica membrana aracnóidea. Entre estes estão os vasos sanguíneos e os grupos de células epiteliais sustentados por fibras reticulares.

Bloom e Fawcett (1977) expõem que as células epiteliais da parte tuberal incluem células indiferenciadas e algumas pequenas células basófilas e acidófilas. O principal componente é uma célula que varia de colunar a cubóide, a qual pode alcançar de 12 a $18 \mu \mathrm{m}$ de tamanho e conter numerosos grânulos pequenos ou algumas vezes pequenas gotículas de colóide. As mitocôndrias são bastonetes curtos, e podem ser encontradas numerosas gotículas de lipídeos. Essas são as únicas células da hipófise do adulto que contêm grandes quantidades de glicogênio. As células podem estar distribuídas sob a forma de estruturas tais como 
folículos. Também podem ser encontradas ilhotas de células epiteliais planas, com 50 a $70 \mu \mathrm{m}$ de extensão. A despeito da ocorrência de uma parte tuberal em todos os vertebrados estudados, as células epiteliais não possuem nenhuma função hormonal característica conhecida.

Segundo Bloom e Fawcett (1977), a neurohipófise consiste em uma população intrínseca de células, chamadas pituícitos, e porções terminais dos axônios pertencentes aos neurônios secretores extrínsecos, cujos corpos celulares estão localizados no hipotálamo. O volume de sua substância é completado por um grande feixe de, aproximadamente, 100.000 fibras nervosas não mielinizadas que compreendem o tracto hipotálamo-hipofisário. Este tracto origina-se do núcleo supra-óptico do hipotálamo junto ao quiasma óptico, e do núcleo paraventricular na parede do terceiro ventrículo, com contribuições menores de outras áreas hipotalâmicas. As fibras dessas fontes convergem sobre a eminência média e caminham sob a haste infundibular no processo infundibular. Ai, não terminam sobre as células nervosas ou outras células efetoras, mas terminam em relação íntima com os vasos do rico plexo capilar da parte nervosa.

Em toda a neurohipófise - mais particularmente abundantes no processo infundibular - estão as massas esféricas de grande variedade de tamanho que se coram intensamente com hematoxilina-alúmen de cromo. Essas massas são chamadas de corpos de Herring. Estes são conhecidos como locais de acumulo de material de neurossecreção no citoplasma das fibras do tracto hipotalâmico-hipofisário.

Brodal (1979), para o homem, cita que as células epiteliais da adenohipófise, embora de tipos diferentes, são circundadas por uma ampla trama de capilares sinusóides. Com base em seu aspecto aos cortes corados por hematoxilina-eosina, é comum distinguir entre células acidófilas (ou eosinófilas), basófilas e neutrofilas (ou cromófobas), cerca de 40, 10 e 50\%, 
respectivamente. É possível mais uma divisão em tipos celulares. Parece haver crescentes evidências de que haja tantos tipos celulares quantos hormônios no lobo anterior, cada tipo sendo relacionado a um hormônio.

Os principais elementos celulares do lobo posterior são os chamados pituicitos. Em certa época, supôs-se que eles representavam os elementos secretores da neurohipófise. Presumivelmente eles representam um tipo particular de célula glial, mas seu papel funcional ainda não está claro.

Os chamados corpos de Herring, particularmente grandes, freqüentemente de forma irregular, são corpos granulares ou homogêneos visíveis em cortes histológicos comuns da neurohipófise, parecendo ser acúmulos particularmente grandes de material neurossecretor presentes como dilatações, na terminação das fibras nervosas.

Willians et al. (1995) relatam para o homem que a adenohipófise é muito vascularizada e constituída de células epiteliais de tamanho e forma variados, dispostos em cordões ou folículos irregulares, separados uns dos outros por sinusóides de paredes finas e suportados por esqueleto de tecido reticular delicado.

As identidades das células endócrinas que secretam os diferentes hormônios adenohipofisários foram intensamente procuradas por diversas técnicas de coloração. Técnicas mais antigas usavam o critério simples da afinidade das células para corantes acidíferos e básicos, tais como o orange-G e a fucsina aldeídica, respectivamente. As células que se coravam fortemente eram cromofílicas; aquelas com pouca afinidade pelos corantes eram cromofóbicas. Células cromofílicas eram classificadas como acidófilas (células $\alpha$ ) ou basófilas (células $\beta$ ). Modificações usando complexas técnicas de coloração de estágios múltiplos distinguiram posteriormente muitas subcategorias de células, cada uma com sua própria matriz tintorial. Tais técnicas, aplicadas particularmente às glândulas pituitárias, quer 
considerando-se aspectos experimentais ou patológicos (alterações hormonais), foram usadas para associar tipos específicos de células com hormônios específicos. Entretanto, muitas incertezas permaneceram, devido à dificuldade na padronização de corantes e na classificação de infinitas variações menores em diferentes indivíduos e espécies.

Junqueira (2004) descreve para o homem que, ao contrário da neurohipófise, que mantém as características de tecido nervoso, a porção originada do ectoderma tem a aparência típica de uma glândula endócrina cordonal com capilares sinusóides.

Encontram-se dois grupos principais de células nesta região:

* Células contendo grânulos citoplasmáticos que possuem grande afinidade pelos corantes histológicos usuais. Estas células estão geralmente situadas à margem dos capilares e foram denominadas cromófilas.

* Células sem grânulos citoplasmáticos visíveis ao microscópio óptico, de citoplasma reduzido e pouco corado, denominadas cromófobas.

As células cromófobas, devido à ausência de grânulos visíveis ao microscópio óptico, foram por muito tempo consideradas células indiferenciadas sem atividade secretora. Com a microscopia eletrônica foi possível ver que a maioria dessas células contém grânulos de secreção. Admite-se, pois, que a maioria das células descritas como cromófobas seja realmente de células secretoras cromófilas, na fase em que contém poucos grânulos de secreção no citoplasma.

Um outro grupo de células da pars distalis, que poderiam ser classificadas como cromófobas, são as células foliculares, assim chamadas porque às vezes tomam a forma cubóide e formam pequenos cistos ou folículos. Mas, em geral, sua forma é estrelada, apresentando extensos prolongamentos citoplasmáticos que se interconectam. Seu citoplasma é claro, sem grânulos, e sua função é desconhecida. 
As células cromófilas, segundo a afinidade de seus grânulos por corantes ácidos e básicos, foram divididas em acidófilas e basófilas.

\section{PARS TUBERALIS}

Esta região tem a forma de um funil, sobreposto ao infundíbulo da hipófise, constituindo, juntos, o pedúnculo da glândula. É constituída por células sem grânulos de secreção e algumas células basófilas e acidófilas pequenas. Elas se dispõem em compridos cordões ao longo dos vasos, podendo-se, às vezes, notar a presença de pequenos folículos formados por estas células, contendo substância amorfa.

\section{PARS INTERMEDIA}

É, no homem, uma região rudimentar composta de células fracamente basófilas. A fissura resultante da bolsa de Rathke raramente é encontrada no adulto, mas em seu lugar aparecem folículos revestidos por epitélio cúbico, contendo colóide no seu interior, denominados cistos de Rathke.

A neurohipófise é formada principalmente por axônios de neurônios do hipotálamo. Contém escassas células do tecido conjuntivo e possui ainda células neurogliais, denominadas pituícitos.

Os pituícitos têm forma irregular, com prolongamentos. O citoplasma destas células contém filamentos intermediários cuja composição é semelhante à dos filamentos intermediários dos artrócitos. Pode também conter gotículas lipídicas ou pigmento. Os pituícitos não têm características de células secretoras; admite-se que seu papel seja semelhante ao da neuroglia. Muitos prolongamentos dos pituícitos terminam nos espaços perivasculares.

Didio (2002) descreve para o homem que a neurohipófise consiste de células (pituícitos) entremeadas com o trato hipotálamo-hipofisário e com terminações nervosas que 
contêm secreção.

O parênquima da parte distal consiste de cordões anastomosados e lâminas de células epiteliais sustentadas por uma membrana basal. Entre os cordões, existem capilares dilatados. As células estão divididas em dois tipos principais: são cromófobas, as que se coram pouco, e cromófilas, as que se coram mais intensamente. As cromófobas são células inativas que contêm relativamente poucos grânulos de secreção. Por meio de técnicas apropriadas, podem ser distinguidos dois tipos diferentes do cromófobas. As cromófilas são maiores que as cromófobas, cujos grânulos de secreção podem ter afinidade por corantes ácidos (acidófilos) ou básicos (basófilos). As células acidófilas ocorrem em maior número do que as basófilas, mas essa relação varia em cada porção da parte distal, e a relação pode ser alterada pela remoção de outras glândulas endócrinas, como a tireóidea e as gônadas.

Com métodos apropriados de coloração podem ser identificados dois tipos distintos de células acidófilas; o microscópio eletrônico permitiu identificar três tipos diferentes de basófilas.

A parte tuberal contém células basófilas ligeiramente granulosas. A parte intermédia não é particularmente importante nos mamíferos, de acordo com os conhecimentos atuais. Possui células poliédricas que se coram com corantes básicos. Algumas células contêm grânulos de secreção. Encontram-se freqüentemente cistos cheios de substância colóide.

\subsection{Microscopia Eletrônica de Transmissão}

Bloom e Fawcett (1977) relatam que os estudos microscópicos eletrônicos têm mostrado que os grânulos específicos das células, na adenohipófise, diferem de maneira 
significativa em tamanho. O tamanho e a forma são, contudo, critérios valiosos para a distinção dos tipos celulares nas micrografias eletrônicas.

As células acidófilas ou células alfas, no homem, são arredondadas ou ovuladas com 14 a $19 \mu \mathrm{m}$ de diâmetro, com um aparelho de Golgi bem desenvolvido e uma pequena mitocôndria em forma de bastonete. Seus grânulos refráteis são bastante grandes e podem ser observados ao microscópio óptico, se separados de modos adequados. Nas preparações rotineiras, coram-se pela eosina, de modo que esta categoria de células é facilmente identificada em tais preparações. Estas células estão, geralmente, dispostas em grupos ao longo dos sinusóides. Dois tipos de células acidófilas podem ser distinguidos num número de espécies mamíferas, baseando-se em método de coloração especial, tamanho do grânulo ou outro critério: Células Somatotróficas e Células Mamotróficas

As células Somatotróficas contêm numerosos grânulos esféricos densos, de 350 a 400 nm de diâmetro. Freqüentemente, as cisternas do retículo endoplasmático granular são paralelas à superfície celular, mas ocasionalmente constituem sistemas concêntricos.

As células Mamotróficas tendem a estar distribuídas individualmente no interior dos cordões celulares. Seus grânulos têm de 550 a 615 nm de diâmetro e freqüentemente mostram contorno irregular.

As células basófilas ou células beta, da parte anterior da glândula, coram-se fracamente com hematoxilina e é menos fácil identificar-las nas preparações de rotina do que as células acidófilas. As basófilas parecem compreender pelo menos dois tipos celulares distintos: as células tireotróficas e as células gonadotróficas.

Bloom e Fawcett (1977) ainda, relata que as células dispostas em grupos no centro da glândula tem forma alongada ou poligonais e são classificadas como Tireotróficas, não estando em contato com os sinusóides, mas, sim, profundamente situadas, nos cordões. Nas 
micrografias eletrônicas, seus grânulos estão entre os menores, sendo seu diâmetro de 140 a 160nm; seu contorno é um tanto irregular, e são menos densos que os outros grânulos, tendendo a reunir-se na periferia da célula.

As células classificadas como Gonadotróficas (ou Delta) são maiores que as outras e de formato arredondado. Geralmente estão situadas junto aos sinusóides. Contém um aparelho de Golgi justanuclear proeminente e um retículo endoplasmático bem desenvolvido, com cisternas sinuosas que estão freqüentemente distendidas por um conteúdo homogêneo de baixa densidade. Os grânulos são esféricos e apresentam de 150 a 250 nm de diâmetro.

As células cromófobas (ou células de reserva) são pequenas e estão localizadas em grupos no interior dos cordões celulares. Geralmente têm menos citoplasma que as células cromófilas, mas raras vezes atingem as dimensões das acidófilas ou basófilas. Tradicionalmente estas células têm sido consideradas isentas de grânulos específicos, mas as micrografias eletrônicas revelam relativamente poucas células com grânulos inespecíficos. Parece provável que muitas das células, identificadas como cromófobas ao microscópio óptico são, na realidade, células cromófilas parcialmente desgranuladas. Algumas cromófobas contêm um aparelho de Golgi característico das acidófilas, enquanto que noutras o aparelho de Golgi lembra o das basófilas. É provável que muitas das cromófobas visíveis já sejam determinadas e capazes de se diferenciarem apenas num dos tipos de cromófilas, ou sejam tipos celulares que contêm grânulos tão pequenos que não possam ser evidenciados ao microscópio óptico.

Um tipo semelhante é a célula Corticotrófica que se encontra distribuída em pequenas quantidades por toda a glândula. Estas células têm forma irregularmente estrelada, com prolongamentos celulares que se estendem entre e parcialmente em torno das células vizinhas à extremidade final das paredes dos sinusóides. O citoplasma nas micrografias eletrônicas 
mostra baixa densidade e retículo endoplasmático um tanto escasso. Relativamente poucos grânulos acumulam-se nessas células. Os que estão presentes possuem de 200 a $250 \mathrm{~nm}$ de diâmetro e estão localizados, na maioria, logo abaixo da membrana celular. Essa localização periférica dos grânulos e a forma irregular das células são valiosos critérios de identificação (Siperstein, Nakayama e Shelton).

No relativo à parte intermediária, Bloom e Fawcett (1977) citam que as células são poligonais ou prismáticas e mostram-se basófilas em suas propriedades tintoriais. Ao microscópio óptico, seus núcleos e organelas citoplasmáticas não têm forma incomum e assemelham-se aos das basófilas da parte distal. No citoplasma há pequenos grânulos (200 a $300 \mathrm{~nm}$ ), dificilmente visíveis ao microscópio óptico, mas visíveis na microscopia eletrônica. Nos mamíferos, geralmente, a parte intermediária é muito pouco vascularizada. No homem, numerosas anastomoses entre as artérias hipofisárias inferiores e superiores atravessam a parte intermediária e esta parte da hipófise recebe alguns suprimentos sanguíneos de uma rica rede capilar da camada do tecido conjuntivo que a separa de modo incompleto do lobo neural. Esse plexo é contínuo com o leito capilar do lobo neural, mas também apresenta algumas conexões com os sinusóides da parte distal.

As fibras nervosas penetram na parte intermediária pelo lobo neural e ramificam-se entre as células.

Os neurônios de secreção, segundo Bloom e Fawcett (1977), ao microscópio eletrônico revelaram características citológicas comparáveis às das outras células que secretam proteínas. O retículo endoplasmático granular (substâncias de Nissl) é abundante e, provavelmente, é o local da síntese hormonal. O produto hormonal, provavelmente é secretado pelo aparelho de Golgi na membrana aderida aos grânulos secretores elétrondensos, de 120 a $200 \mathrm{~nm}$ de diâmetro. Grânulos do mesmo tipo são encontrados em acúmulos 
irregulares ao longo dos axônios destinados à neurohipófise. Na parte nervosa, porções de axônios bastante dilatadas são densamente empacotadas com os grânulos. Estas, sem dúvida, correspondem aos corpos de Herring observados à microscopia óptica nos cortes corados com hematoxilina-alúmen de cromo.

Os corpos de Herring da microscopia óptica e os grânulos densos de 120 a $200 \mathrm{~nm}$ observados nas microscopias eletrônicas representam o material de neurossecreção que se forma nas células dos núcleos paraventricular e supra-óptico do hipotálamo e destes é transportado ao longo das fibras nervosas armazenando-se nos seus terminais no processo infundibular.

As ramificações terminais dos axônios no lobo neural apóiam-se na lâmina basal dos capilares. As células endoteliais que formam as paredes dos capilares da parte nervosa, como as da parte distal e de outras glândulas endócrinas, são extremamente delgadas e contêm fenestras circulares fechadas só por diafragmas delgados. Além dos grânulos densos neurossecretores as terminações nervosas possuem acúmulos de pequenas vesículas semelhantes às encontradas nos terminais sinápticos em outra parte do sistema nervoso. Os grânulos de secreção nunca aparecem livres no espaço perivascular e podem não ser liberados como tais pelas terminações nervosas.

Os pituícitos encontram-se distribuídos entre as fibras nervosas no processo infundibular. No homem apresentam tamanho e forma muito variáveis e contêm, geralmente, grânulos pigmentares que reduzem diretamente a prata ou tornam-se escurecidos com os métodos de Bielschowsky e Hortega. Os estudos microscópicos eletrônicos vieram esclarecer bastante a natureza doa pituícitos, sua relação estrutural com as fibras nervosas é semelhante às das células neurogliais do sistema nervoso central. Os prolongamentos citoplasmáticos distribuem-se ao acaso entre grupos de axônios secretores pré-terminais e quase sempre 
envolvem intimamente sua expansões preenchidas por grânulos (corpos de Herring). Muitos prolongamentos dos pituícitos terminam no espaço perivascular, ao longo das extremidades nervosas.

Brodal (1979) relata, para o homem, que é possível observar os pituícitos interconectados por terminais providos de grânulos neurossecretores. Estes podem pertencer às fibras do núcleo supra-óptico-paraventricular.

Warwick e Willians (1995), analisando células cromófilas do tipo gonadotróficas, em humano, puderam observar que elas possuem núcleos pleomórficos e grânulos esféricos, com cerca de $200 \mathrm{~nm}$ de diâmetro, que tendem a juntar-se em linhas sob a face da célula durante a atividade secretora, além de um retículo endoplasmático granular vesiculoso e um complexo de Golgi muito desenvolvido.

Junqueira (1999) relata, para o homem, que o estudo das células cromófilas ao microscópio eletrônico mostrou que todas apresentam característica de células secretoras com retículo endoplasmático rugoso e complexo de Golgi desenvolvidos e contendo grânulos de secreção. Cada tipo celular apresenta, porém, características que permitem sua identificação ao microscópio eletrônico.

A distribuição dos diversos tipos celulares na glândula não é homogênea; as células acidófilas predominam na periferia, enquanto as basófilas ocupam de preferência a porção central da glândula.

A proporção das células desta glândula pode variar dentro de certos limites devido a fatores tais como idade e estados funcionais ou patológicos - como, por exemplo, gravidez, tireoidectomia, hipertireoidismo e castração. 


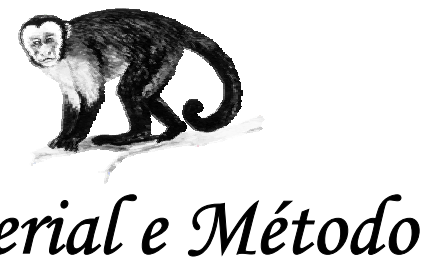

3 Material e Método 
$\mathrm{Na}$ realização deste trabalho enfocamos o macaco Cebus apella, num total de 11 animais (5 machos e 6 fêmeas, adultos), sendo 7 destes cedidos do acervo de pesquisa do laboratório de Anatomia da Universidade Federal de Uberlândia, sob a responsabilidade do Prof. Dr. Zenon Silva. Este material constou de cadáveres fixados e conservados em solução aquosa de formol a $10 \%$. Os outros 4 animais foram obtidos, após óbito, junto ao IBAMAMG.

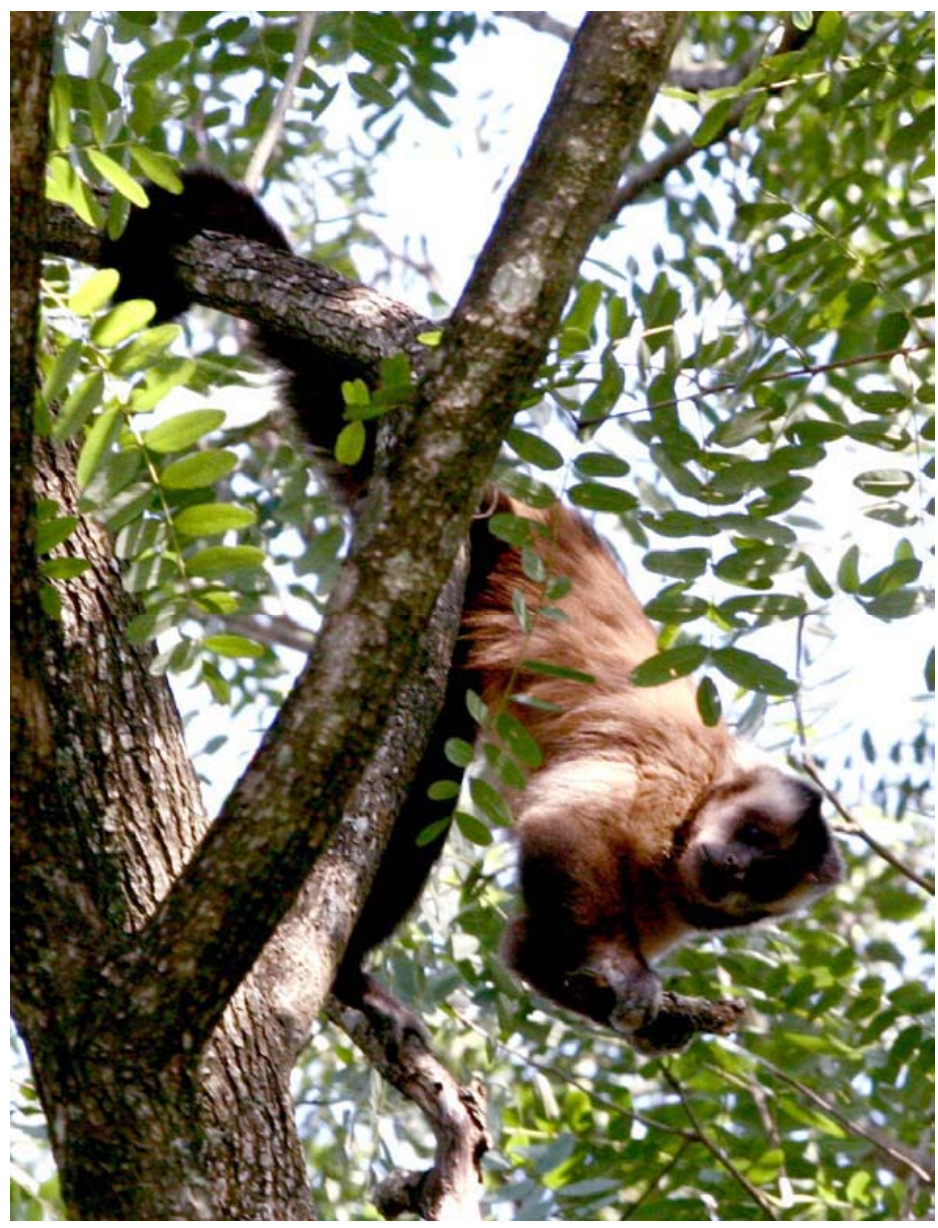

Figura 1- Espécime adulto de Cebus apella 


\subsection{Anatomia Macroscópica}

Para isolamento do encéfalo, a calota craniana foi removida em fragmentos, mediante a utilização de osteótomo, preservando-se a integridade das meninges encefálicas e de todo o tecido encefálico de interesse.

A exposição total da hipófise deu-se com a remoção do osso esfenóide e conseqüentemente, da sela túrcica, acompanhada do diafragma da sela.

Os encéfalos, bem como a hipófise, foram pesados e medidos. As mensurações obtidas do peso, comprimento e largura dos encéfalos e hipófises foram analisadas estatisticamente, através do teste $t$ de Student (pareados e não paramétricos) utilizando-se do programa GraphPad Prism (versão 3.0 Graphpad Software, Inc) para cálculo de média, desvio padrão, correlações e confecção de gráficos, estando os dados expostos na Tabela 1 e na Figura 2 no capitulo de resultados.

Para dissecação foi necessário instrumental para microcirurgia e lupa, sendo que todas as etapas foram fotodocumentadas.

\subsection{Microscopia de Luz}

Para esta etapa foram utilizadas 7 hipófises, sendo 4 destas previamente fixadas em solução aquosa de formol a 10\%, e preparadas conforme técnica a seguir, para embebição em parafina: 
1) As glândulas foram imersas em álcool absoluto I (30 min.), II (30 min.) e III (40 min.), em xilol I (30 min.), II (30 min.) e III (30 min.) e na estufa foram imersas em parafina I (30 min.), II (30 min.) e III (30 min.) sendo posteriormente emblocadas em parafina.

2) Estes blocos foram cortados em micrótomo Reichert - Jung 820 - II em secções de $5 \mu \mathrm{m}$ e as lâminas foram colocadas em estufa $\left(48^{\circ} \mathrm{C}\right)$ para secarem por 2 horas.

3) Os cortes foram corados com Hematoxilina-Eosina, Hematoxilina de Verhoeff, Azul de Anilina e Orange-G e Picrossirius utilizando-se seguinte o protocolo:

- As lâminas foram desparafinizadas em Xilol I, II e III por 15 min em cada solução; Hidratadas com passagens rápidas no álcool absoluto I, II e III, álcool $95 \%, 85 \%$ e $70 \%$, água corrente por 20 min. e água destilada por 5 $\min$.

- Hematoxilina-Eosina: as lâminas ficaram imersas em Hematoxilina por 15 min., água corrente por 20 min., água destilada por 5 min., Eosina 1.30 min. e lavadas rapidamente em água destilada.

- Picrossirius: as lâminas ficaram imersas em picrossirius por $45 \mathrm{~min}$. em $60^{\circ}$, água corrente por $5 \mathrm{~min}$., Hematoxilina de Harris por $5 \mathrm{~min}$., e lavadas rapidamente em água corrente por $5 \mathrm{~min}$.

- Hematoxilina verhoeff: as lâminas ficaram imersas em Hematoxilina verhoeff por $20 \mathrm{~min}$., água corrente por $5 \mathrm{~min}$., cloreto de ferro por $8 \mathrm{~min}$., água corrente por 5 min.,álcool $95 \%$ rápido, hipossulfito de sódio por 5 min., e lavadas rapidamente em água corrente.

- As lâminas coradas com Azul de anilina e Orange-G após desparafinizadas foram tratadas pelo mordente de Bicromato de potássio - 
acido acético por $17 \mathrm{~h}$, lavadas em água corrente por 10min., coradas pela Hematoxilina de Mayer por 10 min., diferenciadas em álcool- ácido clorídrico, lavadas em água corrente até os cortes ficarem de cor azul pálido, coradas novamente pela Fucsina ácida por 10 min., lavadas em água corrente por $5 \mathrm{~min}$, lavadas em água destilada por $5 \mathrm{~min}$., coradas pelo azul de anilina e orange-G- ácido fosfomolibidico por 15 min., lavadas em água corrente por $5 \mathrm{~min}$.

4) Em seguida todas as lâminas foram desidratadas em séries crescentes de álcool $70 \%$ a Xilol III; montadas e colocadas em estufa $\left(48^{\circ} \mathrm{C}\right)$ para secarem por 2 horas.

Das 3 glândulas restantes, 2 foram previamente fixadas em Carnoy $(60 \mathrm{ml}$ de álcool absoluto, 30ml de clorofórmio, 10ml de ácido acético) por 24 horas e 1 foi fixada em solução aquosa de formol a $10 \%$.

1) As glândulas foram lavadas em água corrente e desidratadas em álcool absoluto em 3 séries de $30 \mathrm{~min}$.

2) Incluídas em solução infiltradora de historresina ou resina pura (50ml de resina básica +1 pacote $(0,5 \mathrm{~g})$ de ativador com agitador magnético) $-1^{\mathrm{a}}$ infiltração em resina pura usada por 2 horas e $2^{\mathrm{a}}$ infiltração em resina pura por 24 horas.

3) As glândulas foram então incluídas em $15 \mathrm{ml}$ de resina pura $+1 \mathrm{ml}$ de endurecedor (hardener) em banho de gelo, sendo os blocos colados em suporte de madeira para serem cortados.

4) Em seguida foram efetuados cortes de $3 \mu \mathrm{m}$ de espessura em micrótomo Leica 2065 - Supercut.

5) Os cortes, já em lâminas, foram hidratados por 5 min. em água corrente ou água destilada e corados por $1 \mathrm{~min}$ em azul de toluidina a $0,5 \%$. 
6) Em seguida as lâminas foram colocadas em estufa $\left(48^{\circ} \mathrm{C}\right)$ para secarem por 1 hora, sendo a seguir cobertos, os cortes, com lamínulas.

As lâminas foram observadas e analisadas ao microscópico Olimpus BX60, com aumentos de 4, 10, 20, 40, 60 e 100 vezes, sendo algumas selecionadas para fotodocumentação.

Todos os protocolos foram retirados do livro de técnicas histológicas de Bancroft e Gramble (2002).

\subsection{Microscopia Eletrônica de Transmissão}

Para esta etapa utilizamos 01 glândula que foi fixada por imersão em solução de Karnowsky modificada (glutaraldeído 2,5\%, paraformaldeído 2\%) em tampão cacodilato de sódio 0,1M (cacodylic acid sodium salt trihydrate purum P.A.-Fluka) em pH 7,3 (FERREIRA, 2001) por 30 minutos. Após esse tempo, o fixador foi renovado e o material foi seccionado em fragmentos menores, os quais permaneceram no mesmo fixador por um período de 24 horas a $4^{\circ} \mathrm{C}$. Os fragmentos foram lavados, duas vezes, em tampão cacodilato de sódio $0,1 \mathrm{M}$ por 30 minutos a $4^{\circ} \mathrm{C}$. Foram pós-fixados em tetróxido de ósmio a $1 \% \mathrm{em}$ tampão cacodilato de sódio 0,1 M pH 7,3 com ferrocianeto de potássio (Merck S. A. Inds. Químicas, Rio de Janeiro, Brasil) a 1,5\% durante 60 minutos, à temperatura ambiente. Após duas passagens em solução tampão cacodilato de sódio, os fragmentos foram desidratados em série crescente de álcool (álcool 50\% - 10 minutos; álcool 70\% - 10 minutos, 2X; álcool 80\% - 10 minutos, 2X; álcool 95\% - 10 minutos, 2X, álcool absoluto por 15 minutos, 3X; acetona/álcool (1:1) por 15 minutos e finalmente imersos em acetona por 15 minutos, $2 \mathrm{X}$. 
A seguir iniciou-se a pré-fixação, que foi realizada lentamente, em três etapas utilizando-se a mistura acetona e resina à base de Epon (Epon 812- Fluka Chemie, Buchs, Switzerland). Durante a primeira e segunda etapas o material foi mantido em mistura de ecetona/ resina Epon na proporção de 2:1 e 1:1 (v/v), respectivamente, e em cada concentração ficou imerso por 24 horas (vidros tampados); na terceira etapa utilizou-se a proporção de 1:2 (v/v) de acetona/resina Epon (vidros abertos), durante cerca de 4 horas, em estufa a $37^{\circ} \mathrm{C}$. Posteriormente foram submetidos à infiltração com resina plena (vidros abertos), durante cerca de 4 horas, em estufa a $37^{\circ} \mathrm{C}$.

Finalmente os fragmentos foram incluídos e mantidos em estufa a $60^{\circ} \mathrm{C}$ por 72 horas, para a polimerização da resina e conseqüentemente endurecimento.

Os blocos com o material incluído foram aparados e preparados para microtomia (Reichert-Jung). Cortes semi-finos de $5 \mu \mathrm{m}$ foram corados com azul de toluidina, analisados para selecionar-se a melhor área para a ultramicrotomia.

O material foi cortado no ultramicrótomo. Estes cortes foram acondicionados em telas próprias, corados com acetato de uranila e citrato de chumbo e analisados ao microscópio eletrônico de transmissão EM-109 (Zeiss) do Centro de Microscopia Eletrônica (CEME) da Universidade Federal de Uberlândia. 


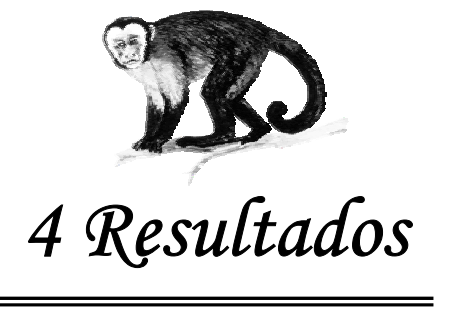




\subsection{Anatomia Macroscópica}

A hipófise do macaco Cebus apella é uma glândula intracranial, bastante desenvolvida, localizada na base do encéfalo, entre o quiasma óptico, rostralmente, e os corpos mamilares, caudalmente (Figura 3). Está fixada à base do cérebro através de um longo pedúnculo, o infundíbulo da hipófise, mas em 02 casos observamos que este infundíbulo é muito curto (3,0 mm de comprimento e 2,0 $\mathrm{mm}$ de largura), mantendo-se a hipófise justaposta ao mesmo.

Parcialmente separada da base do cérebro por uma prega de dura-máter, o "diafragma da sela", a hipófise aloja-se em uma depressão óssea denominada sela túrcica, localizada na face interna do osso esfenóide.

Foram realizadas avaliações do peso e mensurações tanto nos encéfalos quanto nas hipófises (Tabela 1) tendo sido, estes dados, analisados estatisticamente. Registramos também os valores médios do peso, comprimento e largura dos encéfalos (556,4 mg; 61,09 mm; 49,0 $\mathrm{mm}$, respectivamente) e da hipófise $(49,22 \mathrm{mg} ; 3,95 \mathrm{~mm} ; 4,81 \mathrm{~mm})$. Nenhuma correlação significativa foi encontrada entre os valores de peso e largura do encéfalo e hipófise (peso: $r=$ $0,5978 ; \mathrm{p}=0,0521 ;$ largura: $\mathrm{r}=0,5950 ; \mathrm{p}=0,0535)$. Porém, uma baixa correlação foi observada para os valores de comprimento $(r=0,6691 ; p=0,0243)$ como demonstrado pelo coeficiente de correlação de Pearson (Figura 2). 
Tabela 1 - Análise dos Encéfalos e das Hipófises do macaco Cebus apella, Peso em miligramas e comprimento e largura em milímetros

\begin{tabular}{|c|c|c|c|c|c|c|c|}
\hline \multirow[b]{2}{*}{ Espécimes } & & \multicolumn{3}{|c|}{ Encéfalos } & \multicolumn{3}{|c|}{ Hipófise } \\
\hline & $\mathrm{M} / \mathrm{F}$ & Peso & Comp. & Largura & Peso & Comp. & Largura \\
\hline 01 & M & 662,2 & 68,00 & 50,00 & 49,00 & 4,00 & 5,00 \\
\hline 02 & $\mathrm{M}$ & 392,2 & 49,00 & 42,00 & 45.00 & 3,50 & 4,00 \\
\hline 03 & $\mathrm{~F}$ & 396,9 & 54,00 & 44,00 & 47,00 & 3,50 & 4,00 \\
\hline 04 & $\mathrm{M}$ & 690,8 & 67,00 & 49,00 & 63,00 & 5,00 & 6,00 \\
\hline 05 & $\mathrm{~F}$ & 594,2 & 61,00 & 51,00 & 48,90 & 4,00 & 5,00 \\
\hline 06 & $\mathrm{~F}$ & 594,1 & 61,00 & 50,00 & 48,87 & 4,00 & 5,00 \\
\hline 07 & $\mathrm{~F}$ & 480,0 & 68,00 & 50,00 & 49,00 & 4,00 & 5,00 \\
\hline 08 & $\mathrm{~F}$ & 580,0 & 61,00 & 51,00 & 48,65 & 4,00 & 5,00 \\
\hline 09 & M & 580,0 & 60,00 & 51,00 & 48,00 & 4,00 & 5,00 \\
\hline 10 & $\mathrm{M}$ & 570,0 & 63,00 & 51,00 & 48,00 & 4,00 & 5,00 \\
\hline 11 & $\mathrm{~F}$ & 580,0 & 60,00 & 50,00 & 46,00 & 3,50 & 4,00 \\
\hline Média & -- & 555,4 & 61,09 & 49,00 & 49,22 & 3,95 & 4,81 \\
\hline $\begin{array}{l}\text { Desvio } \\
\text { Padrão }\end{array}$ & -- & 96,02 & 5,77 & 3,06 & 4,76 & 0,415 & 0,603 \\
\hline
\end{tabular}

$\mathrm{M}=$ macho

$\mathrm{F}=$ fêmea

Comp. $=$ comprimento 

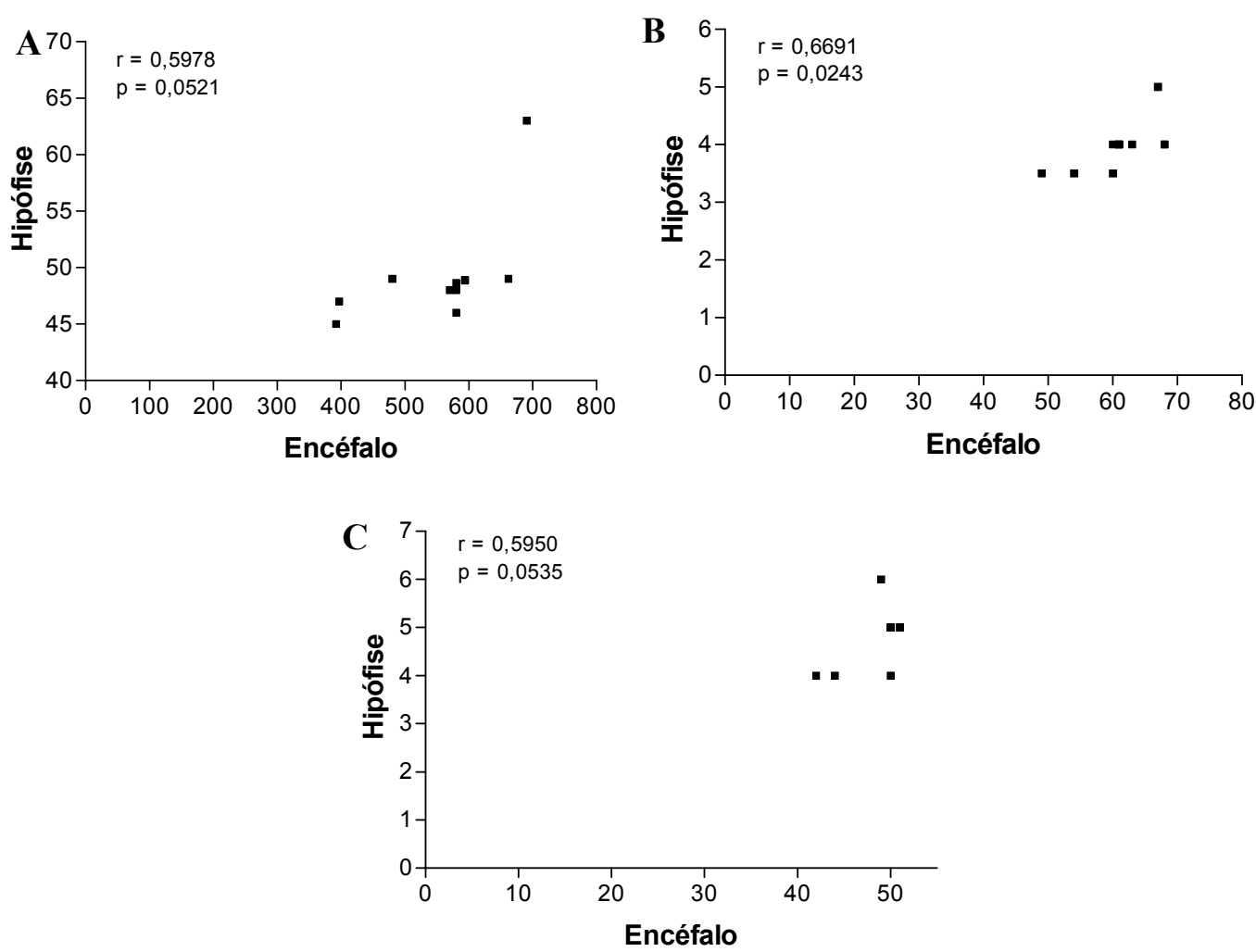

Figura 2 - Correlação entre valores de peso (A), Comprimento (B) e Largura (C) dos encéfalos e hipófises do macaco Cebus apella

A hipófise do macaco Cebus apella exibe forma odontóide, em vista ventral, isto é, tem a forma aproximada da coroa de um dente incisivo humano. Surge aparentemente como massa única, mas é possível identificar-se, ainda que discretamente, uma divisão em lobos, um anterior, e outro posterior (Figura 3).

Das relações da hipófise, consideramos que ela se projeta sob os corpos mamilares, mantendo com estes, íntima relação, assim como com o diafragma da sela, enquanto a face ventral apóia-se sobre o leito da sela túrcica. Rostralmente à hipófise encontra-se o quiasma óptico. 
Em nosso material, observamos divisão discreta da hipófise, em um lobo anterior e outro posterior, além do infundíbulo que adere à eminência hipotalâmica. (Figura 4). 


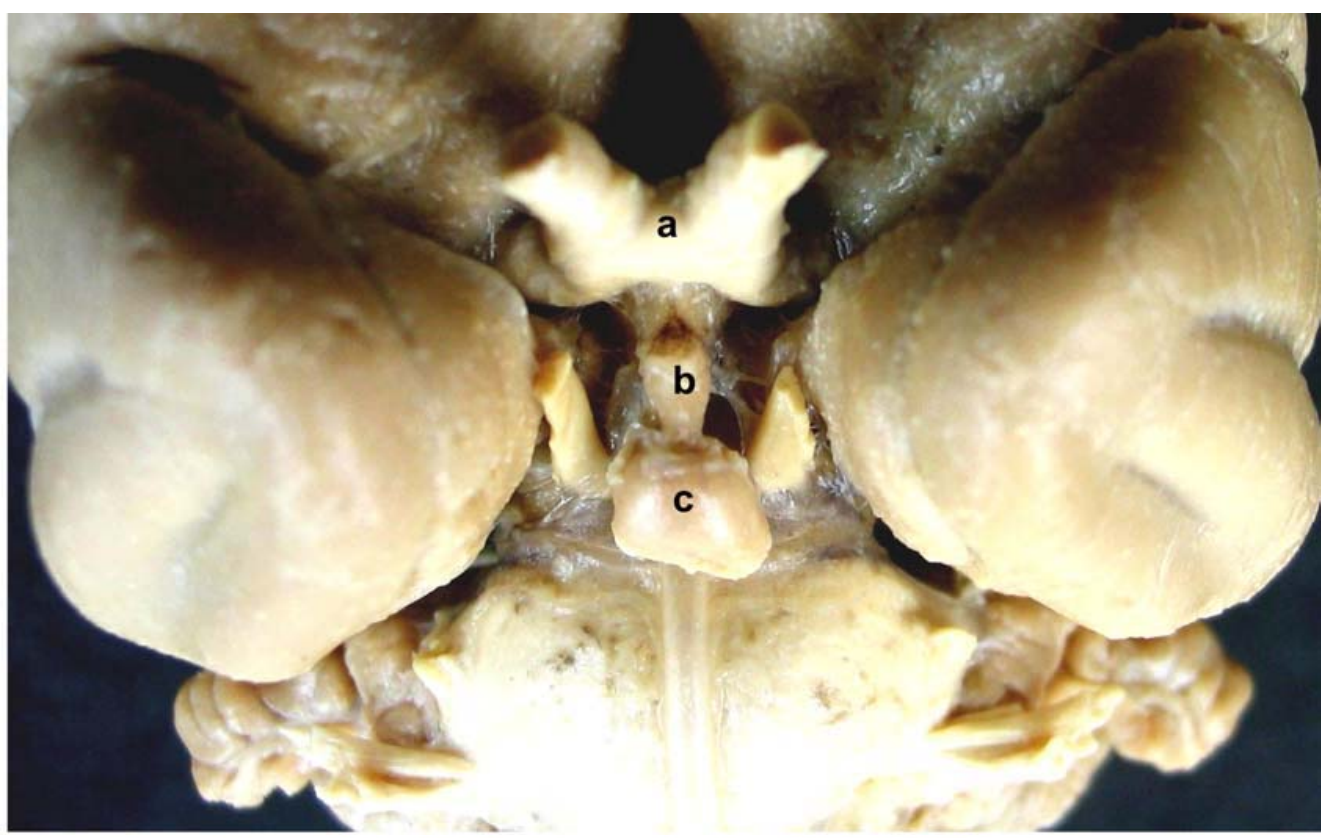

Figura 3- Vista ventral de encéfalo de macaco Cebus apella. a- quiásma óptico; binfundíbulo da hipófise; c- hipófise

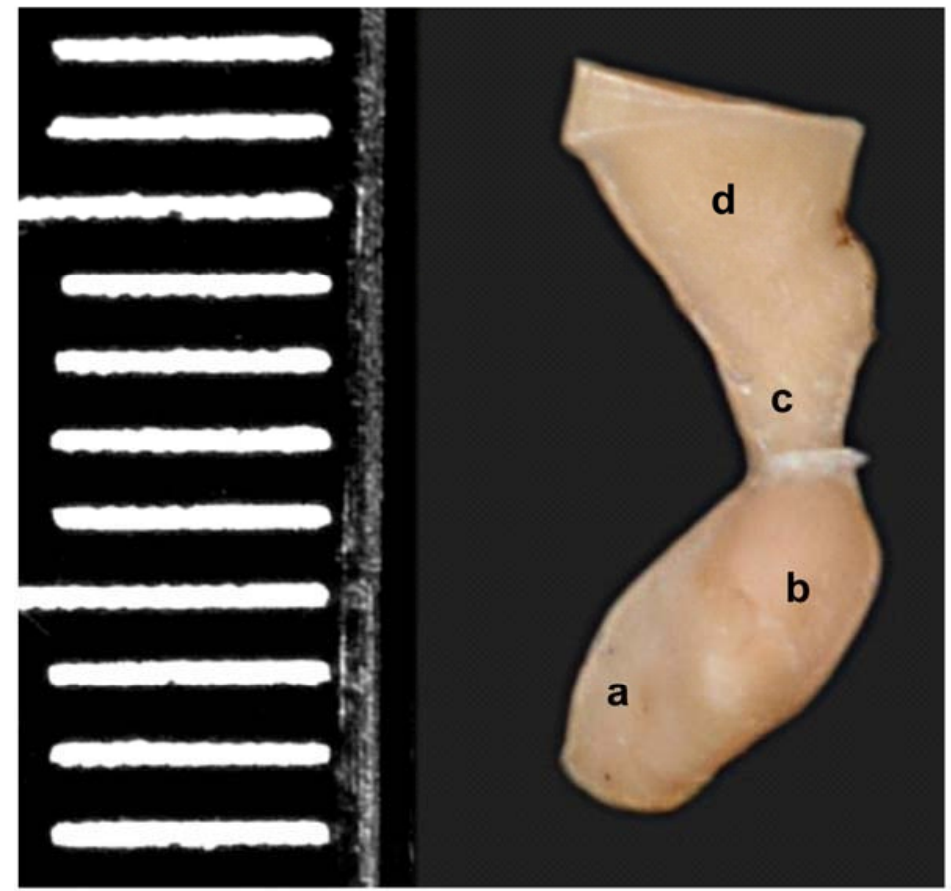

Figura 4- Vista lateral esquerda de hipófise de macaco Cebus apella. a- adenohipófise; bneurohipófise; c- infundíbulo da hipófise; deminência hipotalâmica 


\subsection{Microscopia de Luz}

À microscopia de luz observou-se que a glândula é envolvida por uma cápsula de fibras colágenas (Prancha 1 - Figura A), além de se confirmar a relação da hipófise com o hipotálamo.

A análise microscópica permitiu a verificação de que, ao lobo anterior corresponde a adenohipófise e ao lobo posterior, a neurohipófise. Permitiu, ainda, a identificação de uma porção intermediária entre estes dois lobos, a parte intermediária e do infundíbulo.

O infundíbulo está constituído por uma porção neural, a haste infundibular e uma parte tuberal, semicircundante, que é uma continuação da adenohipófise em direção ao hipotálamo, porém não chegando a atingi-lo. A adenohipófise ou porção glandular é a maior parte da hipófise. No componente neural, neurohipófise, podemos observar semelhança de sua estrutura com o tecido cerebral e com a haste infundibular.

Entre estas duas porções, adenohipófise e neurohipófise, encontra-se a parte intermédia que freqüentemente apresenta uma cavidade, a fenda hipofisária (Prancha 1 Figura B e C).

\section{Adenohipófise}

A adenohipófise é composta por grandes cordões celulares circundados por uma expressiva rede de capilares (sinusóides).

As células do parênquima da adenohipófise estão divididas em dois grupos: as cromófobas e as cromófilas. Apesar das cromófobas não se corarem bem, os núcleos são demonstráveis e aparecem agrupados, sendo seu citoplasma, reduzido (Prancha 1 - Figuras D). 
As cromófilas, por meio de sua afinidade com os corantes histológicos, podem ser classificadas em duas categorias: as acidófilas $(\alpha)$ e as basófilas $(\beta)$.

As acidófilas, quando coradas com Hematoxilina-Eosina apresentam-se coradas em roxo ou são menos avermelhadas; quando coradas com Azul de Toluidina coram-se em azul claro e, em laranja, quando coradas por Azul de anilina e Orange G (Prancha 1 - Figuras D, E e F).

As basófilas, quando coradas com Hematoxilina-Eosina apresentam-se de cor rosa e são mais avermelhadas; com o Azul de Toluidina coram-se em azul escuro e em azul claro quando coradas por Azul de anilina e Orange G (Prancha 1 - Figuras D, E e F).

A adenohipófise apresenta muitas fibras colágenas, que lhe conferem um aspecto lobular, pois separam os seus grupos celulares, o que também foi verificado com as células da parte intermédia (Prancha 1 - Figura G).

\section{$>$ Parte Intermédia}

A parte intermédia é caracterizada por células basófilas maiores e mais alongadas que as células da adenohipófise e com pouca delimitação celular (Prancha 2 - Figura H). Da mesma forma, as células estão envoltas por colágeno e formando agrupamentos celulares (Prancha 2 - Figuras H, J e K). Foram observados ainda folículos preenchidos por substância coloidal (Prancha 2 - Figura I) e raramente foram encontrados em pontos distintos envoltos por células cubóides (Prancha 2 - Figura L).

\section{Neurohipófise}

A neurohipófise é composta de células alongadas, os pituícitos, com prolongamentos citoplasmáticos e núcleos que tendem à forma oval. $\mathrm{O}$ parênquima da neurohipófise assemelha-se em estrutura, ao tecido neural, no relativo à presença de inúmeras fibras neurais visíveis nos cortes corados com azul de toluidina. Ainda podemos observar agrupamentos de 
grânulos contidos em dilatações nas terminações destas fibras, os corpos de Herring. As fibras neurais e os prolongamentos dos pituícitos formam a trama celular da parte nervosa (Prancha 3 - Figura M). Verificamos um agrupamento de células basófilas, em todos os espécimes analisados, tanto na neurohipófise quanto no infundíbulo (Prancha 3 - Figura N e O). Notamos ainda, a presença de vasos sanguíneos juntamente com fibras colágenas próximas aos mesmos (Prancha 3 - Figura P).

A porção neural do infundíbulo (haste infundibular) apresentou o mesmo padrão de células da neurohipófise (Prancha 3 - Figura P, Q e R). 


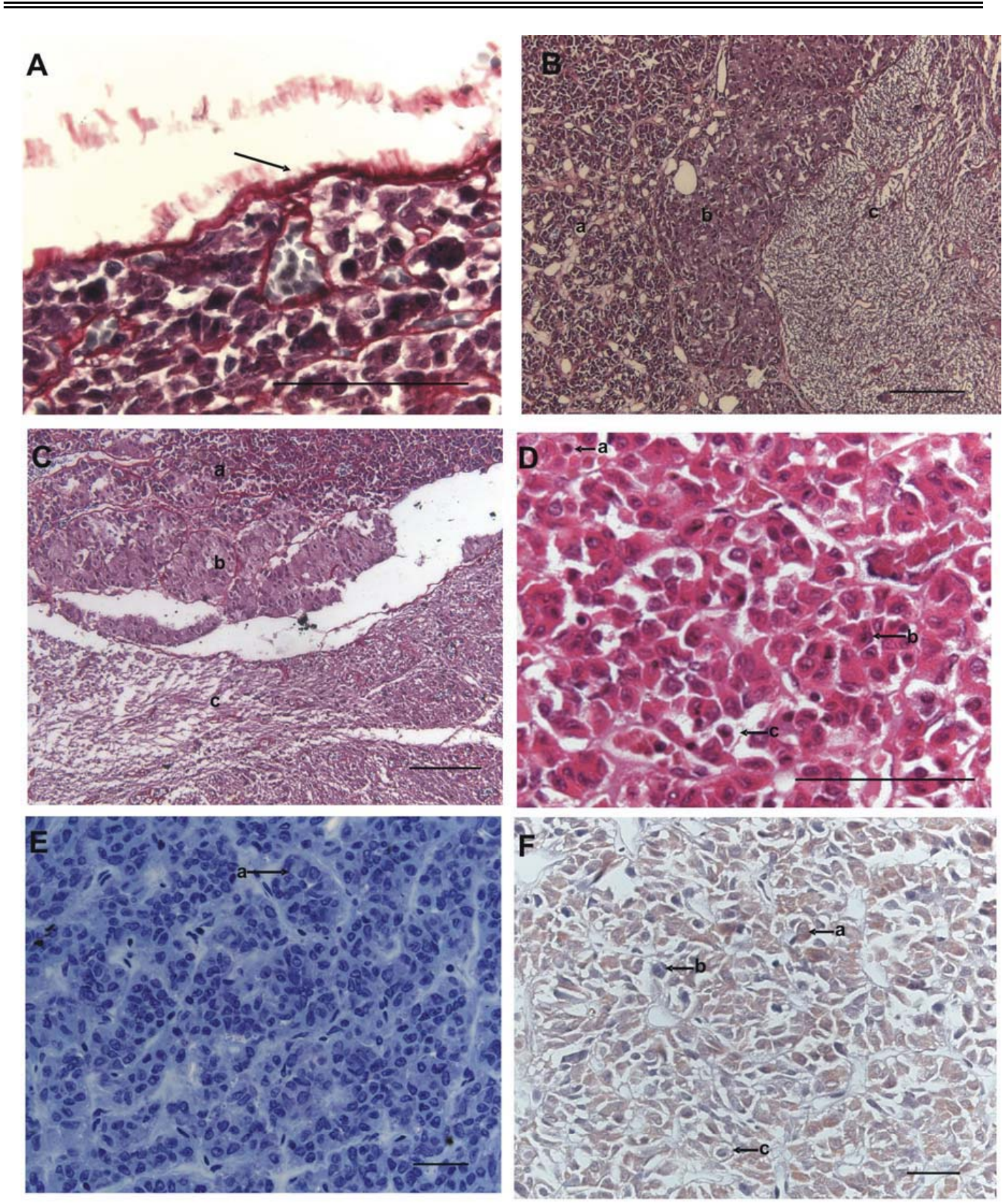

Prancha 1-Fotomicrografias demonstrando cápsula de colágeno da hipófise (A); as três porções da hipófise a- adenohipófise, b-porção Intermédia, c- neurohipófise (B e C); células da adenohipófise a- acidófila, b- basófila, c- cromófoba (D e F); cordões celulares da adenohipófise (E); Picrossirius (A, B e C), Hematoxilinaeosina (D), Azul de toluidina (E), Azul de Anilina e Orange-G (F). Escala de barra: 20X (em B e C); 60X (em E e F); 100X (Ae D) 
4 Resultados 62
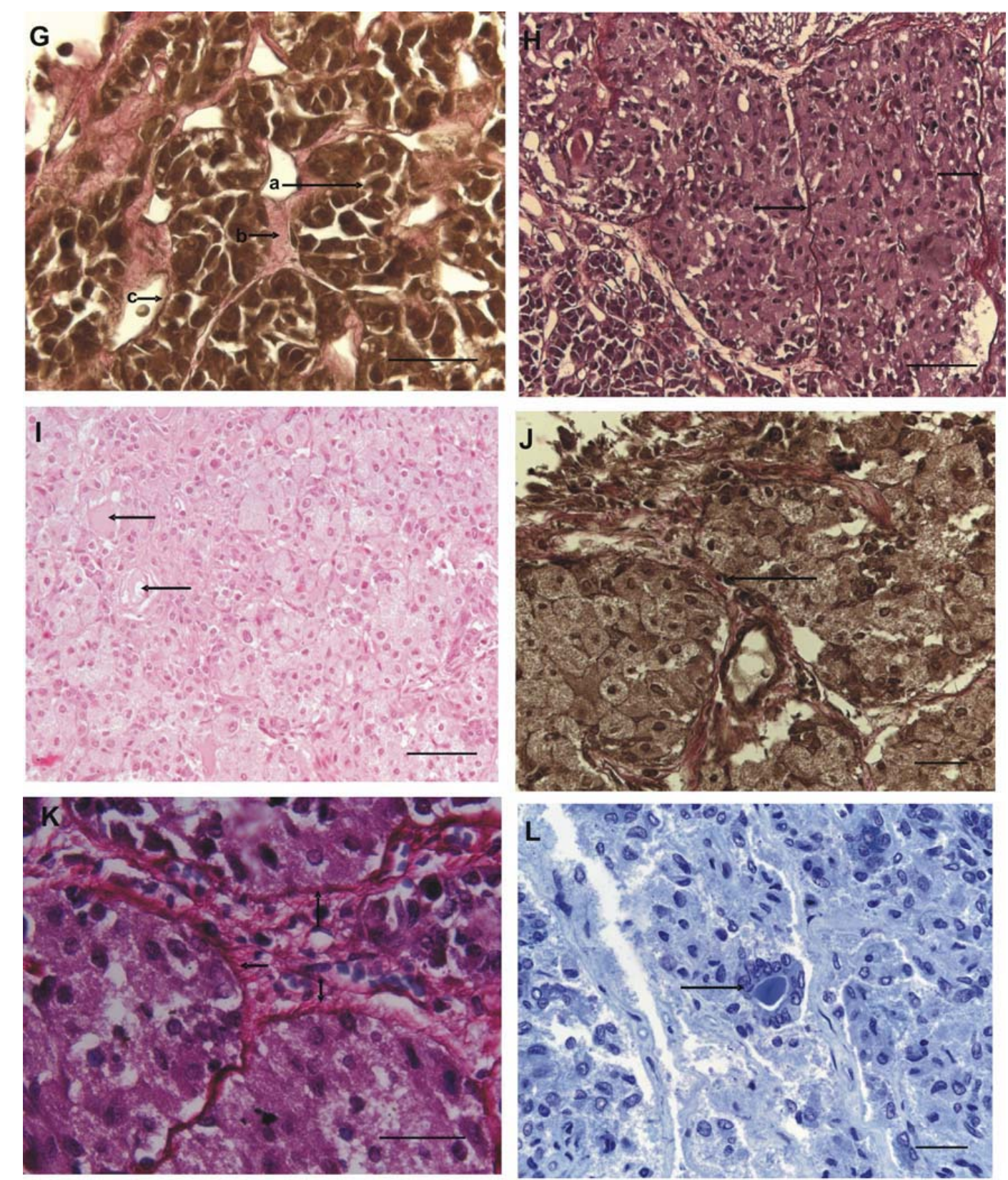

Prancha 2- Fotomicrografias demonstrando células da adenohipófise a- cordões celulares, b- fibras colágenas, c- fibras elásticas (G); parte intermédia, disposição em lobos circundados por fibras elásticas - setas (H, J e K), folículos com colóides -setas (I) e folículo com colóide circundado por células cubóides -setas (L). Picrossirius ( $\mathrm{He} \mathrm{K}$ ), Hematoxilina-eosina (I), Azul de toluidina (L), Hematoxilina de Verhoeff ( $\mathrm{G}$ e J). Escala de barra: 40X (em He I); 60X (L); 100X (K) 

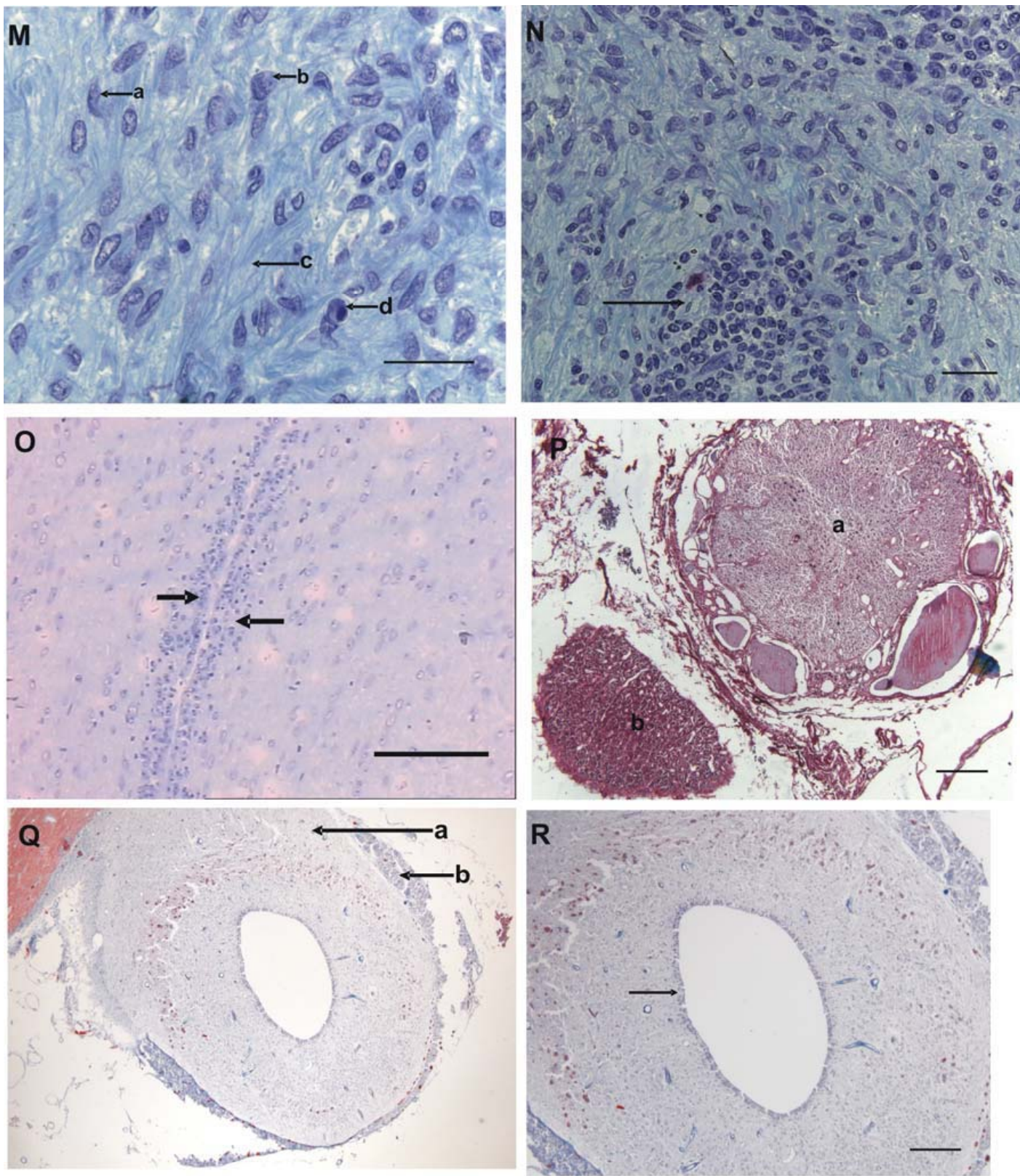

Prancha 3-Fotomicrografias demonstrando células da neurohipófise ( $\mathrm{M}$ e N), apituícitos, b- corpos de Herring, c- fibras neurais, d- células basófilas (M), seta- agrupamento de células basófilas da neurohipófise $(\mathrm{N})$, setaagrupamento de células basófilas do infundíbulo (O); Fotomicrografias demonstrando relação do infundíbulo e parte tuberal (P e Q), disposição das células no infundíbulo (R). Azul de toluidina ( $\mathrm{M}, \mathrm{Ne} \mathrm{O})$ Picrossirius (P), Azul de anilina e orange-G (Q e R). Escala de barra: 4X (Q);10X (em O, P e R); $100 \mathrm{X}(\mathrm{M})$ 


\subsection{Microscopia Eletrônica de Transmissão}

A microscopia eletrônica de transmissão permitiu-nos identificar tipos celulares distintos.

Quanto aos aspectos gerais observamos que estas células não se agregam e seus núcleos ocupam grande parte do citoplasma exibindo morfologia irregular (esféricos, ovais ou achatados) com profundas invaginações de sua membrana (Prancha 4 - Figura A).

A maioria das células apresentou grânulos de tamanho variável, não sendo possível a identificação de uma membrana perigranular, em nenhum dos tipos celulares.

A hipófise apresenta 4 tipos celulares diferentes (tipo I, II, III e IV), levando-se em consideração a presença de grânulos de secreção em seu interior e as características encontradas em seus núcleos.

São os seguintes os tipos celulares identificados:

\section{Células do tipo I}

Estas células podem ainda ser divididas em dois grupos:

Tipo $\mathbf{I}_{\mathbf{A}}$ - São células que apresentam grânulos esféricos dispersos pelo citoplasma, e núcleos com invaginações na membrana nuclear que induzem à formação de lóbulos (Prancha 4 - Figura B).

Tipo $\mathbf{I}_{\mathbf{B}}-$ Apresentam as mesmas características das células anteriores, porém observou-se neste tipo celular, a presença de grânulos pequenos eletrón-densos e grânulos grandes eletrón-lúcidos no centro, com halo eletrón-denso na periferia (Prancha 4 - Figura C e D). 


\section{Células do tipo II}

Apresentam núcleos lobulados semelhantes ao observado nas células do tipo I. No entanto, seus grânulos foram visualizados, mais frequentemente, próximos à membrana citoplasmática (Prancha 5 - Figura E).

\section{* Células do tipo III}

Essas células são alongadas e seu núcleo acompanha a forma celular. Quando apresentam grânulos, eles são aparentemente menores que nas demais células (Prancha 5 - Figura F).

\section{Células do tipo IV}

São células de forma irregular com núcleo denteado apresentando em seu citoplasma grânulos minúsculos, quase imperceptíveis, em relação aos demais tipos celulares, lembrando células cromófobas (Prancha 5 - Figura G). 
4 Resultados 66
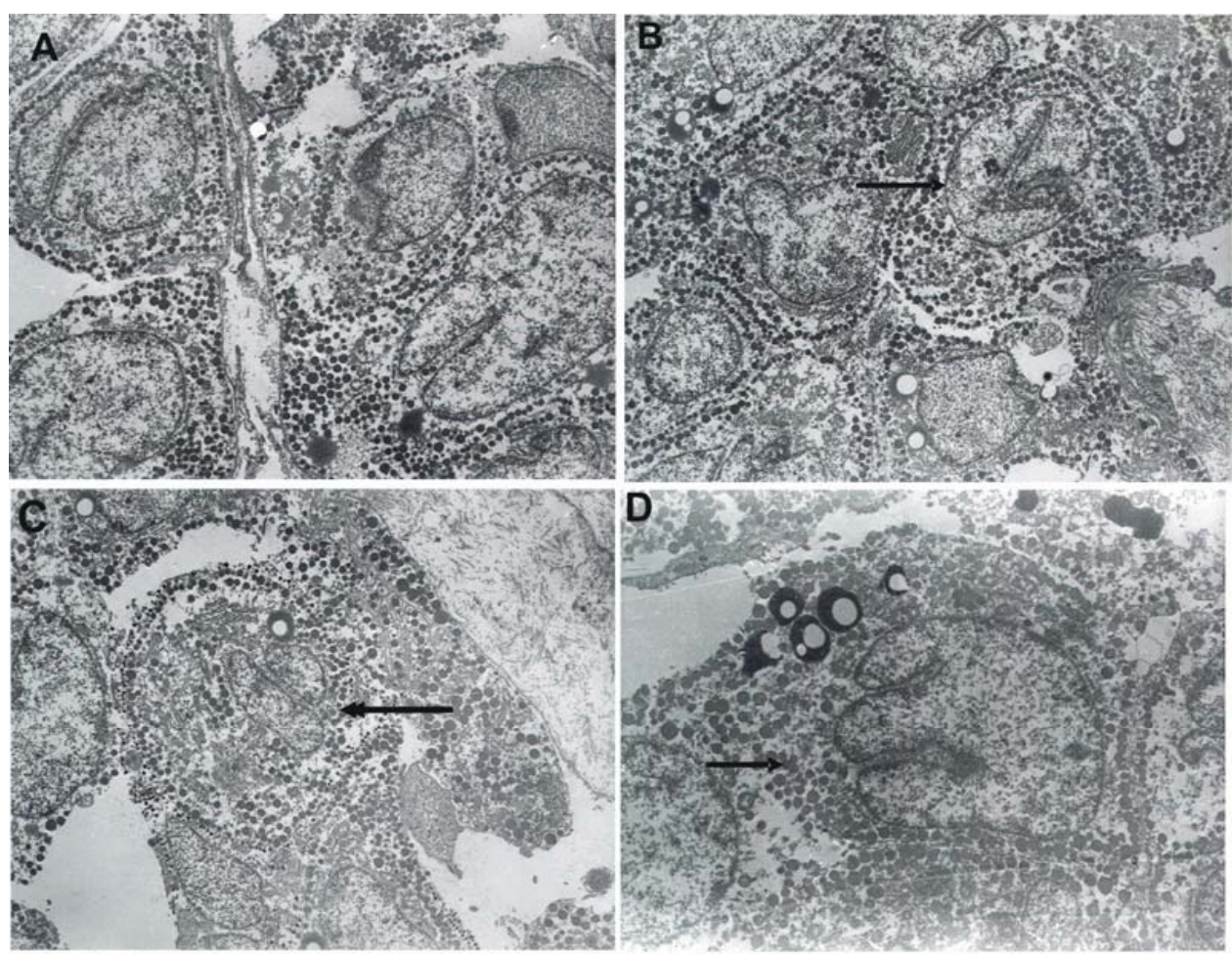

Prancha 4- Eletromicrografia dos tipos celulares da hipófise do macaco Cebus apella. Anúcleos com profundas invaginações em sua membrana, B- células do tipo IA; C e D- células do tipo IB; 7.353X (A, B, e C), 11.850X (D). 
4 Resultados 67

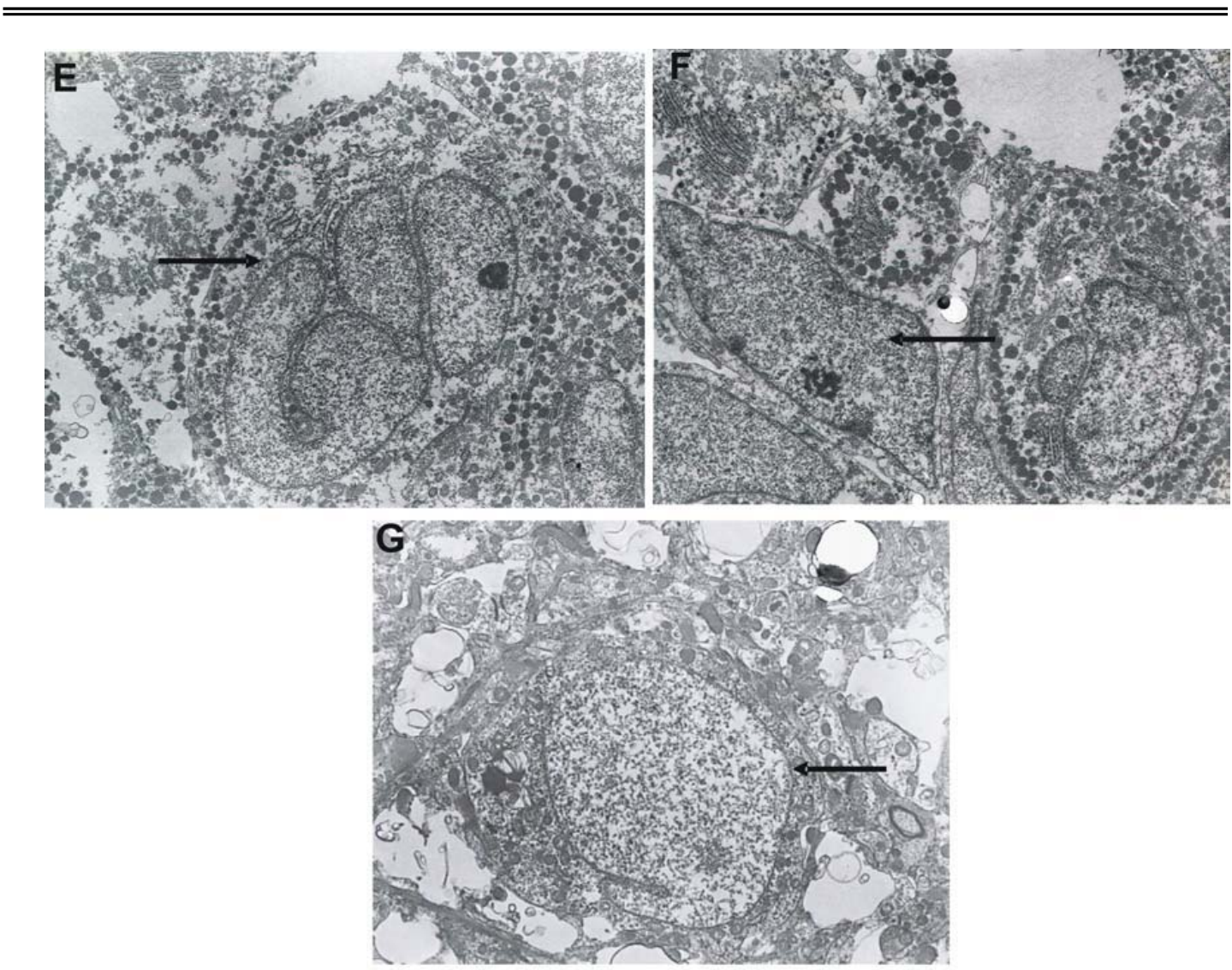

Prancha 5- Eletromicrografia dos tipos celulares da hipófise do macaco; Cebus apella .E - célula do tipo II; F-células do tipo III; G-célula do tipo IV. 11850X. 


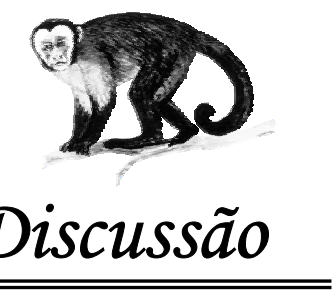




\subsection{Anatomia Macroscópica}

Miller e Leonard (1932) para o macaco Rhesus; Hill (1955) para Tarsius; Bloom e Fawcett (1977), Brodal (1979), Willians et al. (1995), Didio (2002); Junqueira (2004) e Baker (1962) para o homem, descrevem que, assim como observamos no macaco Cebus apella, a hipófise é uma glândula intracranial, localizada na base do encéfalo, parcialmente separada da base do cérebro por uma prega de dura-máter, o "diafragma da sela", alojando-se em uma depressão óssea, a sela túrcica, localizada na face interna do osso esfenóide.

Didio (2002) cita, em relação ao ser humano, que a glândula relaciona-se superiormente com o quiasma óptico e com os tractos ópticos, lateralmente com a artéria carótida interna e as outras estruturas do seio cavernoso. O seio esfenoidal, situado inferior e anteriormente à hipófise e a camada óssea existente entre essas duas estruturas freqüentemente é fina, dados estes que conferem com os nossos achados para o Cebus apella, o que também foi verificado por Miller e Leonard (1932) para o macaco Rhesus; por Hill (1955) para Tarsius; por Bloom e Fawcett (1977), Brodal (1979), Willian et al. (1995), Didio (2002) e Junqueira (2004), para o homem.

Para o Cebus apella descrevemos que a hipófise está fixada à base do cérebro através de uma longa haste, o infundíbulo da hipófise, fato este verificado por todos os autores na literatura consultada. Hill (1957) para Hapale jacchus, H. penicillata e Tamarinus nigricollis; Hill (1972) para Alouatta cita que esta glândula é provida de uma curta haste principal, o que também observamos em dois casos com mensuração de 3,0 mm de comprimento e 2,0 $\mathrm{mm}$ de largura, mantendo-se portanto, a hipófise, justaposta à região hipotalâmica. 
Foram realizadas avaliações do peso e mensurações tanto nos encéfalos quanto nas hipófises, encontrando-se, os dados individuais, na tabela 1. Registramos também os valores médios do peso, comprimento e largura dos encéfalos (556,4 mg; 61,09 mm; 49,0 mm, respectivamente) e da hipófise $(49,22 \mathrm{mg} ; 3,95 \mathrm{~mm} ; 4,81 \mathrm{~mm})$. Pela análise estatística desses dados, pelo coeficiente de correlação de Pearson, nenhuma correlação significativa foi encontrada entre os valores de peso e largura do encéfalo e hipófise (peso: $\mathrm{r}=0,5978 ; \mathrm{p}=0,0521$; largura: $\mathrm{r}=$ 0,5950; $\mathrm{p}=0,0535)$. Porém, uma baixa correlação foi observada para os valores de comprimento $(r=0,6691 ; p=0,0243)$. Apesar de ter sido encontrada uma relativa correlação entre os valores de comprimento, não podemos afirmar que este fato seja importante já que o valor de $r$ estabilizou-se em 0,66 e sabemos que para se firmar uma correlação expressiva, o ideal teria sido um valor que se aproximasse de 1,00 .

Quando comparamos as mensurações da hipófise do Cebus apella, que é um animal de pequeno porte, com aquelas correspondentes a outros primatas, parece-nos ser, essa glândula, relativamente grande. Assim, para macacos de porte mais avantajado, como o Rhesus, Miller e Leonard (1932) apontam os valores de 4,00 mm para o comprimento e de 6 a $7 \mathrm{~mm}$ para a largura. Hill (1960), no relativo a Cebídeos, refere às medidas de 2,80 $\mathrm{mm}$ para o comprimento e de 4,50 mm para a largura e Hill (1972) aponta para o Ateles, 4,00 mm para o comprimento e 10,00 mm para a largura. No tocante ao ser humano, Williams et al. (1995) referem os valores de $8,00 \mathrm{~mm}$ para o comprimento e 10,00 $\mathrm{mm}$ para a largura. Diante do exposto podemos entender que esta é uma característica particular do Cebus apella, já que a diferença também é significativa quando comparada a animais de pequeno porte como o verificado por Hill (1966) para Miopithecus (2,80 mm de comprimento e 4,50 mm de largura).

A hipófise do macaco Cebus apella exibe forma odontóide, em vista ventral, isto é, tem a forma aproximada da coroa de um dente incisivo humano, diferentemente do 
encontrado na literatura. Assim, alguns autores descrevem que esta glândula apresenta forma ovóide no macaco Rhesus (MILLER; LEONARD, 1932); forma ovóide e achatada nos Cebideos (Hill, 1960), Ateles e Lagothrix (Hill, 1972); forma globosa para Tarsius (Hill, 1955); globosa e achatada dorso-ventralmente nos Cebídeos e Alouatta (Hill, 1972); circular no Hapale jacchus, H. penicillata e Tamarinus nigricollis (Hill, 1957); formato de ervilha nos Cercopithecus (Hill, 1966) e forma de esfera achatada em Strepsirhini (Hill, 1953).

Embora aparentemente surja como massa única, é possível observar, ainda que discreta, uma divisão em lobos, um anterior, a adenohipófise e outro posterior, a neurohipófise. Essa divisão já é notada pela coloração diferente, das duas porções, que é mais acentuada na adenohipófise.

Didio (2002) explica, e concordamos com ele, que a adenohipófise, é achatada súperoinferiormente e côncava posteriormente (observamos que no Cebus a neurohipófise encaixase nessa concavidade), compreendendo uma parte distal, uma tuberal e uma intermédia. A parte distal, a maior delas, está localizada anteriormente ao lúmen residual; a parte intermédia está situada entre o lúmen residual e a neurohipófise, e a parte tuberal é uma extensão superior da parte intermédia, ao longo do infundíbulo.

Certa confusão surgiu porque a presença da luz residual entre a parte intermédia e a parte distal teria levado muitos autores, como Hill (1955) para Tarsius, Willians et al. (1995) e Junqueira (2004) para o homem, a considerarem a parte intermédia como parte do lobo posterior ou como um lobo em separado.

A neurohipófise deve ser considerada constituída pelo lobo posterior, o infundíbulo (haste) e a eminência mediana do hipotálamo segundo Bloom e Fawcet (1977) e Brodal (1979), em relação ao homem. Pela observação de nosso material, decidimos considerar as divisões da hipófise como sendo a neurohipófise, constituída pelo infundíbulo, a eminência 
mediana e o lobo neural (ou posterior); a adenohipófise que inclui a parte tuberal, a parte distal (glandular) e a parte intermédia.

Ainda sobre o lúmen residual ou fenda hipofisária, existente entre a parte distal e a parte intermédia, podemos supor que apesar de ser um vestígio da bolsa de Rathke e ser presente na vida fetal e no início da vida pós-natal, ela persiste em alguns espécimes, como cita Hill (1955) para os Tarsius e também conforme observamos no Cebus apella.

No Cebus apella, encontramos a parte tuberal localizada na parte inferior do infundíbulo, não formando um colar contínuo ao redor do mesmo, conforme também encontrou Hill (1972) no Ateles palliata No entanto, para Hapale jacchus, H. penicillata e Tamarinus nigricollis (HILL, 1957), para Cebídeos (HILL, 1960), e para o Gorila, Chimpanzé, Papio, Miopithecus e Cercopithecus (HILL, 1966) observou-se que a parte tuberal circunda o infundíbulo formando um colar ao seu redor.

\subsection{Microscopia de Luz}

A literatura sobre os aspectos histológicos da hipófise em primatas de modo geral é escassa, sendo encontrados relatos mais detalhados apenas em relação ao homem.

A adenohipófise ou porção glandular representa a maior parte da hipófise, disposição também relatada por todos os autores consultados. No componente neural, neurohipófise, podemos observar semelhança com o tecido cerebral e com a haste infundibular.

Entre estas duas porções, adenohipófise e neurohipófise, encontra-se a parte intermédia que freqüentemente apresenta uma fenda, a fenda hipofisária. 
Conforme alguns autores, dentre eles Bloom e Fawcet (1977), Brodal (1979), Willians et al. (1995) para o homem, esta fenda é característica em fetos e inicio da vida pós-natal. De fato, Junqueira (2004) afirma que raramente é encontrada no adulto, e que em seu lugar aparecem folículos revestidos por epitélio cúbico, contendo colóide no seu interior, denominados de cistos de Rathke. Observamos em 3 dos espécimes que, aparentemente, esta fenda persistiu. Não podemos, entretanto, afirmar ser a fenda propriamente dita, pois nos espécimes em que não estava presente também não foram encontrados os folículos mencionados por Junqueira (2004). Podemos supor, então, que possa ter ocorrido uma retração do material no ato da preparação, pois esta fenda é descrita pelos autores posicionada entre a parte distal e intermédia, estando esta ultima aderida à neurohipófise e normalmente a encontramos aderida à adenohipófise.

\section{$>$ Adenohipófise}

A adenohipófise é composta por grandes cordões celulares, irregulares, circundados por uma extensa rede de capilares que são revestidos por endotélio e conhecidos como sinusóides, descritos da mesma forma por Bloom e Fawcet (1977), Brodal (1979), Didio (2002), Willians et al. (1995) e Junqueira (2004) para o homem.

As células do parênquima da hipófise, do Cebus apella, estão divididas em dois grupos: as cromófobas e as cromófilas, como também foi descrito por todos os autores mencionados neste trabalho.

Quanto às células cromófobas, do Cebus apella, apesar de não se corarem bem, os núcleos são demonstráveis e aparecem agrupados, sendo seu citoplasma, reduzido. Hill (1953) relata, para Lemur, que estas células foram coradas fracamente por corantes básicos. No entanto, Didio (2002) menciona, para o homem, que estas células, com poucos grânulos de secreção podem ter afinidade por corantes ácidos e básicos, com o que concordamos, haja 
vista que nossas células foram coradas muito fracamente ora por corante ácido, ora por corante básico.

Junqueira (2004) cita a presença de um outro grupo de células da pars distalis, que poderiam ser classificadas como cromófobas. São as células foliculares, assim chamadas porque às vezes tomam a forma cubóide e formam pequenos cistos ou folículos. Mas, em geral, sua forma é estrelada, apresentando extensos prolongamentos citoplasmáticos que se interconectam. Seu citoplasma é claro, sem grânulos, e sua função é desconhecida, contudo não verificamos a presença destas células nos espécimes estudados.

Bloom e Fawcet (1977), para o homem, afirmam que as células glandulares são classificadas como cromófilas e cromófobas, baseando-se na sua avidez ou falta de afinidades por corantes usados nas colorações rotineiras de cortes histológicos. As células cromófilas foram, a princípio, subdivididas em células acidófilas e basófilas, de acordo com as reações tintoriais dos seus grânulos específicos nos cortes corados com hemalúmen e eosina ou com outras combinações de um corante básico e um ácido. Na denominação das células da pituitária, acidófilo e basófilo referem-se apenas às afinidades tintoriais dos grânulos específicos.

As identidades das células endócrinas que secretam os diferentes hormônios adenohipofisários foram intensamente procuradas por diversas técnicas de coloração WILLIANS et al. (1995). As células que se coravam fortemente eram cromofílicas; aquelas com pouca afinidade pelos corantes eram cromofóbicas. Células cromofílicas eram classificadas como acidófilas (células $\alpha$ ) ou basófilas (células $\beta$ ). Modificações usando complexas técnicas de coloração de estágios múltiplos distinguiram posteriormente muitas subcategorias de células, cada uma com sua própria matriz tintorial. Tais técnicas, aplicadas particularmente às glândulas pituitárias, quer considerando-se aspectos experimentais ou patológicos (alterações 
hormonais), foram usadas para associar tipos específicos de células com hormônios específicos. Entretanto, muitas incertezas permaneceram, devido à dificuldade na padronização de corantes e na classificação de infinitas variações menores em diferentes indivíduos e espécies. Brodal (1979) afirma ser o método de Hematoxilina-Eosina o corante mais comum na distinção destas células.

Pelo exposto entendemos a dificuldade que tivemos em diferenciar estas células, para o Cebus apella, pois foram feitos vários testes tentando encontrar um protocolo próprio para a hipófise deste animal. A diferenciação entre as $\alpha$ e $\beta$ a principio pode ser dada pela morfologia da célula que mostra as primeiras sendo menores com núcleos grandes, diferentemente das últimas que possuem forma irregular e seus núcleos são pequenos. No entanto, as duas categorias apresentam delimitação celular.

As cromófilas, por meio de sua afinidade com os corantes histológicos, podem ser classificadas em duas categorias: as acidófilas $(\alpha)$ e as basófilas $(\beta)$. Conforme cita Junqueira (2004), estas células encontram-se situadas à margem dos capilares.

As acidófilas, quando coradas com Hematoxilina-Eosina apresentam-se coradas em roxo ou são menos avermelhadas; com o Azul de Toluidina coram-se em azul claro e em laranja, com o Azul de anilina e Orange G.

As basófilas, quando coradas com Hematoxilina-Eosina apresentam-se de cor rosa e são mais avermelhadas; com o Azul de Toluidina coram-se em azul escuro e em azul claro quando coradas por Azul de anilina e Orange G.

A hipófise do macaco Cebus apella apresenta muitas fibras colágenas, que lhe conferem um aspecto lobular, pois separam os grupos celulares da adenohipófise, o que também foi verificado com as células da parte intermédia, sendo que a própria célula é 
envolvida por uma cápsula de colágeno, o que foi verificado também por Bloom e Fawcet (1977) para o homem. Entretanto, nenhum outro autor teceu comentários sobre este aspecto.

\section{$>$ Parte Intermédia}

A parte intermédia, para o Cebus apella, é caracterizada por células basófilas maiores e mais alongadas que as células da adenohipófise e com pouca delimitação celular. Quanto à basofilia destas células, também concordam Hill (1957), para Hapale e Tamarinus nigricollis, além de Didio (2002) e Junqueira (2004) para o homem. Hill (1957) cita ainda que nesses animais as células desta região são largas, com dimensões semelhantes às das células da parte distal, diferentemente do que encontramos para o Cebus. Observamos que estas células estão envoltas por colágeno formando agrupamentos celulares.

Foram verificados ainda folículos preenchidos por substância coloidal, como o descrito também por Didio (2002), para o homem. Junqueira (2004), por sua vez, descreve a presença de folículos revestidos por epitélio cúbico contendo colóide no seu interior, denominados cistos de Rathke, estruturas estas que aparecem no lugar da fenda hipofisária, no adulto. O surgimento destes cistos não foi observado em nenhum dos espécimes por nós estudados, ainda que possamos admitir a ocorrência de artefatos de técnica, o que explicaria o fato de a parte intermédia mostrar-se ora aderida à adenohipófise ora à neurohipófise, sendo este ultimo comportamento descrito por todos os autores consultados.

\section{$>$ Neurohipófise}

Hill (1957), para Hapale e Tamarinus nigricollis, além de Bloom e Fawcet (1977), Brodal (1979), Didio (2002) e Junqueira (2004) para o homem, descreve que a neurohipófise consiste em uma população de células de forma irregular, com prolongamentos citoplasmáticos, denominadas de pituícitos, entremeados por fibras nervosas. Ainda é possível 
observarem-se dilatações nas terminações nervosas, chamadas de Corpos de Herring, que podem ser classificados também como massas esféricas de grande variedade de tamanho, dispostos por toda neurohipófise. Como se pode observar, os dados da literatura, sobre as células da parte neural são concordes independentemente da espécie, o mesmo podendo-se considerar em relação a nossos resultados, no Cebus apella. Isto significa que esta porção da glândula segue um padrão de comportamento celular.

Podemos ainda, sobre os pituícitos, relatar que estes possuem núcleos mais ou menos ovais, detalhe não descrito pelos autores consultados.

As fibras nervosas e os prolongamentos dos pituícitos formam a trama celular da parte nervosa. Notamos ainda, a presença de vasos sanguíneos juntamente com fibras colágenas próximas aos mesmos, fato mencionado apenas por Bloom e Fawcet (1977) quando relatam, para o homem, que as fibras nervosas terminam em intima relação com os vasos do rico plexo capilar da parte nervosa. No entanto, não citam a presença de fibras colágenas.

Hill (1972), para Atele e Lagothrix, verificou que existe uma tendência das células da parte intermédia migrarem para o infundíbulo, concordando com o verificado por nós e acrescentamos ainda que esta migração inicia-se na neurohipófise. Porém, nenhum autor comentou este fato.

Brodal (1979), para o homem, diz ter encontrado gotículas coloidais de vários tamanhos nos capilares da neurohipófise, o que não foi observado por nós nesta região da hipófise do Cebus apella.

As nossas observações mostraram que o infundíbulo está constituído por uma porção neural, a haste infundibular e uma porção tuberal, circundante. Assim como nós, todos os autores citam da mesma forma em relação à haste infundibular. No referente à parte tuberal, os estudos são mais detalhados. Assim, Junqueira (2004), para o homem, descreve que esta é 
uma região em forma de funil, sobreposta ao infundíbulo, constituindo juntos, o pedúnculo da glândula. Por outro lado, Bloom e Fawcet (1977) citam, ainda para o homem, que a porção mais espessa é aquela sobre a superfície anterior, freqüentemente mostrando-se incompleta na superfície posterior da haste. Concordamos com o exposto por estes autores já que verificamos o mesmo aspecto nos espécimes por nós estudados, diferentemente do encontrado por Hill (1957) para Hapale jacchus, H. penicillata e Tamarinus nigricollis, por Hill (1960) para Cebideos, e por Hill (1966) para o Gorila, Chimpanzé, Papio, Miopithecus e Cercopithecus, autores esses que descrevem a parte tuberal circundando o infundíbulo, formando assim um colar ao seu redor.

\subsection{Microscopia Eletrônica de Transmissão}

Embora tenhamos encontrado inúmeros trabalhos referentes à ocorrência de tumores e à secreção de hormônios relacionados a esta glândula, estes trabalhos não fornecem subsídios suficientes para uma análise comparativa, com os nossos resultados. Assim tivemos dificuldade em discutir este aspecto da histologia devido à escassez de trabalhos específicos de descrição celular.

Conforme Bloom e Fawcett (1977), em seus estudos sobre esta glândula no homem, a microscopia eletrônica de transmissão mostra que os grânulos de secreção das células da hipófise diferem de maneira significativa em tamanho. Estes autores referem que o tamanho e forma dos grânulos são critérios valiosos para a distinção dos tipos celulares. Baseados nesta informação, fizemos comparação entre os grânulos das células que encontramos e juntamente com a forma do núcleo, classificamos estas células nos tipos celulares I, II, III e IV. 
Apesar de termos em mãos trabalhos que nos ajudaram a fazer uma análise comparativa como os esquemas de Norris (1997) para os vertebrados em geral, as figuras exibidas por Bloom e Fawcett (1977), alusivas a ratos, bem como as constantes das publicações de Fiore, Mancini, e Roberts, (1977) e Junqueira (2004), relativas ao homem, não podemos classificar os tipos celulares conforme comumente encontramos (somatotróficas, mamotróficas, tireotróficas, gonadotróficas e corticotróficas).

Por falta de detalhes que pudessem ajudar nesta classificação optamos por considerar os tipos celulares em I, II, III e IV, até mesmo porque quando as comparações eram realizadas focando o tamanho e a forma dos grânulos, as observações eram concordantes. Entretanto, no referente aos núcleos, as diferenças eram marcantes, embora a maioria dos autores não mencione a presença de núcleos denteados conforme o verificado por nós na maioria das células analisadas. Neste ultimo aspecto, apenas Norris (1997) relata em um tipo celular a presença deste núcleo denteado, porém de forma irregular, diferentemente do encontrado por nós, e classifica-o como Corticotrófico.

Podemos supor, então, que estas diferenças possam ter ocorrido, pois as análises foram feitas em outras espécies e não em macacos próximos ao Cebus apella.

As particularidades encontradas na hipófise do Cebus apella acham-se relacionadas, de modo especial, as características próprias das células da adenohipófise, o que nos leva a admitir a possibilidade de realizações de trabalhos futuros que possam estabelecer correlações dessas características celulares, com a produção dos diferentes hormônios secretados por essa glândula. Esperamos que as informações contidas neste trabalho possam ser utilizadas em pesquisas posteriores sobre o assunto, levando sempre em consideração o fato de que ao 
trabalharmos com animais, estas pesquisas precisam contribuir acima de tudo para uma melhor relação do ser humano com a natureza. 
6 Conclusões 
Do que acabamos de expor, julgamos válidas as seguintes conclusões:

A hipófise do macaco Cebus apella, quanto à localização e relações, segue o padrão anatômico já descrito em relação a outros primatas. Porém no que diz respeito à sua forma, difere de toda descrição consultada, apresentando forma odontóide.

Tendo sido analisados estatisticamente os dados obtidos para peso, comprimento e largura dos encéfalos (valores médios de 556,4 mg; 61,09 mm; 49,0 mm, respectivamente) e da hipófise (valores médios de 49,22 $\mathrm{mg} ; 3,95 \mathrm{~mm} ; 4,81 \mathrm{~mm}$, respectivamente), não foi encontrada correlação significativa entre os valores de peso e largura do encéfalo e da hipófise (peso: $\mathrm{r}=0,5978 ; \mathrm{p}=0,0521$; largura: $\mathrm{r}=0,5950 ; \mathrm{p}$ $=0,0535)$. Porém, uma baixa correlação foi observada para os valores de comprimento $(\mathrm{r}=0,6691 ; \mathrm{p}=0,0243)$

A hipófise do macaco Cebus apella mostra-se macroscopicamente como massa única, mas é possível identificar-se uma divisão discreta em um lobo anterior e outro posterior.

A análise microscópica permitiu a verificação de que ao lobo anterior corresponde a adenohipófise e, ao posterior, a neurohipófise, identificando-se entre ambos, a parte intermediária.

$>$ À microscopia de luz a hipófise mostra-se envolvida por uma cápsula de fibras colágenas que se adentram no parênquima dispondo-se, na adenohipófise e na parte 
intermédia, entre cordões celulares, conferindo a essas regiões da glândula, aspecto lobular.

O infundíbulo representa o pedúnculo da glândula e se acha constituído em funil, por uma porção neural, a haste infundibular, por sua vez semicircundada anteriormente pela parte tuberal, dependente da adenohipófise.

A adenohipófise, maior porção da glândula, é composta por cordões celulares circundados por expressiva rede de sinusóides. Suas células são cromófobas e cromófilas, sendo estas acidófilas e basófilas.

Pela microscopia eletrônica de transmissão é possível a identificação, na adenohipófise, de profundas invaginações da membrana nuclear e de tipos celulares distintos (I, II, III e IV), levando-se em conta a disposição de grânulos no citoplasma: tipo Ia - grânulos dispersos no citoplasma; tipo IB - difere do anterior por apresentar grânulos grandes elétrons-lúcidos no centro, com halo elétron-denso na periferia; tipo II - difere do tipo I por apresentar os grânulos dispostos mais freqüentemente na periferia do que na porção central do citoplasma; tipo III - grânulos aparentemente menores que os das células de outros tipos; tipo IV - os grânulos são minúsculos, quase imperceptíveis, lembrando aspecto de células cromófobas.

A parte intermédia da hipófise apresenta células basófilas maiores e mais alongadas que aquelas encontradas na adenohipófise, além de folículos preenchidos por substância coloidal, exibindo ao seu redor células cubóides. 
A neurohipófise é composta por células alongadas (pituícitos) e fibras neurais. Agrupamentos de grânulos - corpos de Herring - são encontrados em dilatações nas terminações dessas fibras.

$>$ A organização morfológica da hipófise do macaco Cebus apella, de modo geral encontra-se inserida no padrão já descrito relativamente a outros primatas, excetuando-se a forma odontóide da glândula e o comportamento da membrana nuclear das células da adenohipófise, caracterizado pela presença de profundas invaginações. 


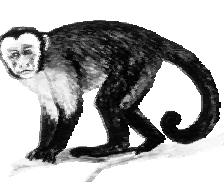

Referências 
AURICCHIO, P. Primatas do Brasil. São Paulo: Terra brasilis, 1995. p. 35.

BANCROFT, J. D.; GRAMBLE, M. Theory and pratice of histological techiniques. 5. ed. Churchill Livingstone: Elsevier, 2002. p. 796.

BARROS, R. A. C.; RIBEIRO, A. R.; PRADA, I. L. S.; SILVA, Z.; SILVA, D. C. O. Constituição do plexo lombar do macaco Cebus apella. Brazilian Journal of Veterinary Research and Animal Science, v. 40, n. 5, p. 373-381, 2003.

BEKER, B. L. Hypothalamic Functions. In: CROSBY, E. C.; HUMPHREY, T.; LAUER, E. W. Correlative anatomy of the nervous system - Hypothalamic Functions: neuroendocrine functions. New York: The Macmillan Company, 1962. p. 323-331.

BLOOM, W.; FAWCETT, D. W. Tratado de histologia. 10. ed. Rio de Janeiro: Editora Interamericana Ltda, 1977. p. $458-475$.

BRODAL, A. Anatomia neurológica com correlações clinicas. 3. ed. São Paulo: Editora Roca, 1979. p. 593-608.

DIDIO, L. J. A. Tratado de Anatomia sistêmica aplicada, v. 2, 2a ed. São Paulo: Editora Atheneu, 2002. p. $589-591$.

FERREIRA, G. L. S. Mastócitos de Colomys callosus e Toxoplasma gondii: uma abordagem in vivo e in vitro de uma infecção experimental. 2001. 137 p. Tese (Mestrado em Imunologia e Parasitologia) - Departamento de Imunologia, Microbiologia e Parasitologia da Universidade Federal de Uberlândia, Uberlândia, 2001.

FIORE, M. S. H.; MANCINI, R. E.; ROBERTS, E. D. P. Novo atlas de histologia Microscopia ótica, Histoquímica e Microscopia Eletrônica. 3. ed. Rio de Janeiro: Guanabara Koogan, 1977. p. 298-305.

\footnotetext{
* Conforme as diretrizes para apresentação de dissertações e teses na Faculdade de Medicina Veterinária e
} Zootecnia da Universidade de São Paulo. 4. ed. rev. atual. e ampl. São Paulo: FMVZ-USP, 2003. 84 p. 
HILL, W. C. O. Primates: comparative anatomy and taxonomy II - Strepsirhini. Edinburgh: University Press, 1953. 78 p.

. Primates: comparative anatomy and taxonomy II - Haplorhini - Tarsoidea.

Edinburgh: University Press, 1955. 59 e 190 p.

. Primates: comparative anatomy and taxonomy III -Pithecoidea - Platyrrhini Hapalidae. Edinburgh: University Press, 1957.168 - 169 p.

. Primates: comparative anatomy and taxonomy IV Cebidae - Part A. Edinburgh: University Press, 1960. 276, $364-365$ p.

Primates: comparative anatomy and taxonomy VI - Catarrhini-

Cercopithecoidea - Cercopithecinae. Edinburgh: University Press, 1966. 45, 342, 611, 647 e 682 p.

Primates: comparative anatomy and taxonomy I - Cebidae - Part B. Edinburgh: University Press, 1972. 216 - 217, 420 p.

JUNQUEIRA, L. C.; CARNEIRO, J. Histologia básica. 10. ed. Rio de Janeiro: Guanabara Koogan, 2004. p. 390-397.

LAPIN, A. B. Use of primates in biomedical research. Acta endocrinologica, v. 166, p. 15-27, 1972. supplement.

MELLO, M. T.; FARIA, D. S. La primatologia en latinoamerica. In: ANALES DO SYMPOSIO DE PRIMATOLOGIA, 1983, Arequia - Peru. p. 249-257.

MILLER, R. A.; LEONARD, S. L. The Endocrine Glands - Hypophysis. In: HARTMAN, C. G.; STRAUS JR., W. L. The Anatomy of the rhesus monkey (Macaca mulatta). New York: Hafner publishing CO, 1932. p. 266-267.

NAPIER, J. P.; NAPIER, P. H. Evolutionary aspects of primate locomotion. American Journal Physiolology Anthropolgy, v. 27, p. 333-341, 1967. 
NORRIS, D. O. Vertebrate endocrinology. 3. ed. San Diego: Academic Press Inc., 1997. p. 104-119.

PIZZUTO, C. S. Vascularização arterial da mandíbula e maxila de primatas eotropicais. 2001. 86 p. Tese (Mestrado em Anatomia dos Animais Domésticos) Faculdade de Medicina Veterinária e Zootecnia, Universidade de São Paulo, São Paulo, 2001.

PRADA, I. L. S. - Bioética e Bem - Estar Animal. Utilização de Animais em Pesquisa e Ensino. In: REUNIÃO DA MORFOLOGIA PANAMERICANA, 11., 2004, Foz do Iguaçu. Anais...

REIS, M. G. Citologia da adenohipófise do gambá Sul-Americano Didelphis azarae. 1988. 80 p. Tese (Doutorado) - Departamento Morfologia. Faculdade de Odontologia de Ribeirão Preto, Universidade de São Paulo, Riberão Preto, 1988.

RIBEIRO, A. R. Estudo anatômico do plexo braquial do macaco Cebus apella Origem, composição e nervos resultantes. 2002. 146 p. Tese (Mestrado em Anatomia dos Animais Domésticos) -Faculdade de Medicina Veterinária e Zootecnia, Universidade de São Paulo, São Paulo, 2002.

RIBEIRO, A. R.; PRADA, I. L. S.; SILVA, Z. CARVALHO-BARROS, R. A.; SILVA, D. C. O. Origem do plexo braquial do macaco Cebus apella, Brazilian Journal of Veterinary research and animal science, v. 42, n. 2, p. 143-149, 2005.

VERAS, M. M. Aspectos morfológicos do aparelho reprodutor em bugios (Alouatta guariba clamitans e Alouatta caraya): o modelo feminino. 2004. 105 p. Tese (Mestrado em Anatomia dos Animais Domésticos) - Departamento de Cirurgia da Faculdade de Medicina Veterinária e Zootecnia da Universidade de São Paulo, 2004.

SANTINI, M. E. L. Observações sobre o comportamento social e reprodutivo e reprodutivo do Cebus apella em cativeiro. A primatologia no Brasil. In: CONGRESSO BRASILEIRO DE PRIMATOLOGIA, 1., 1983, Belo Horizonte. Anais..., Belo Horizonte: [s.n.], 1983. p. 65-69.

WILLIANS, P. L; WARWICK, R.; DYSON, M.; BANNISTER, L. H. Gray Anatomia, v. II - Neurologia. 37 ed. Rio de Janeiro, Editora Guanabara Koogan, p. 1364-1369, 1995. 
Referências 89

WILSON, D. E.; REEDER, D. A. M. Mammal species of the world - A taxonomic and geographic reference. 2. ed. Washington: Smithsonian Institution Press, 1992. 187 p. 